license http://creativecommons.org/licenses/by-nc-nd/4.0/

\title{
1 Structure and reactivity of oxalate surface complexes on lepidocrocite derived from infrared spectroscopy, DFT-calculations, adsorption, dissolution and photochemical experiments
}

\section{Susan C. Borowski ${ }^{a}$, Jagannath Biswakarma ${ }^{a, c}$, Kyounglim Kang ${ }^{b}$, Walter D.C. Schenkeveld ${ }^{b}$, Janet G.} Hering ${ }^{\mathrm{a}, \mathrm{c}, \mathrm{d}}$, James D. Kubicki ${ }^{\mathrm{e}}$, Stephan M. Kraemer ${ }^{\mathrm{b}}$, Stephan J. Hug ${ }^{\mathrm{a}^{*}}$

${ }^{a}$ Eawag, Swiss Federal Institute of Aquatic Science and Technology, Ueberlandstrasse 133, CH-8600 Duebendorf, Switzerland

${ }^{b}$ University of Vienna, Dept. of Environmental Geosciences and Environmental Science Research Network, Althanstraße 14 (UZA II) 1090 Vienna, Austria

${ }^{c}$ Swiss Federal Institute of Technology (ETH) Zürich, IBP, CH-8092 Zürich, Switzerland

${ }^{\mathrm{d}}$ Swiss Federal Institute of Technology Lausanne (EPFL), ENAC, CH-1015 Lausanne, Switzerland

${ }^{e}$ The University of Texas at El Paso, Dept. of Geological Sciences, 500 West University Avenue, El Paso, TX 79968, USA

* Corresponding author. E-mail: stephan.Hug@eawag.ch

Current address of S.C. Borowski: Virginia Military Institute, Lexington, VA 24450, USA. E-mail: borowskisc@vmi.edu

\begin{abstract}
Oxalate, together with other ligands, plays an important role in the dissolution of iron(hdyr)oxides and the bio-availability of iron. The formation and properties of oxalate surface complexes on lepidocrocite were studied with a combination of infrared spectroscopy (IR), density functional theory (DFT) calculations, dissolution, and photochemical experiments. IR spectra measured as a function of time, concentration, and $\mathrm{pH}(50-200 \mu \mathrm{M}$ oxalate, $\mathrm{pH} 3-7)$ showed that several surface complexes are formed at different rates and in different proportions. Measured spectra could be separated into three contributions described by Gaussian line shapes, with frequencies that agreed well with the theoretical frequencies of three different surface complexes: an outer-sphere complex (OS), an inner-sphere monodentate mononuclear complex (MM), and a bidentate mononuclear complex (BM) involving one $\mathrm{O}$ atom from each carboxylate group. At $\mathrm{pH} 6$, OS was formed at the highest rate. The contribution of $\mathrm{BM}$ increased with decreasing $\mathrm{pH}$. In dissolution experiments, lepidocrocite was dissolved at rates proportional to the surface concentration of $B M$, rather than to the total adsorbed concentration. Under UV-light ( $365 \mathrm{~nm}$ ), BM was photolyzed at a higher rate than $\mathrm{MM}$ and OS. Although the comparison of measured spectra with calculated frequencies cannot exclude additional possible structures, the combined results allowed the assignment of three main structures with different reactivities consistent with experiments. The results illustrate the importance of the surface speciation of adsorbed ligands in dissolution and photochemical reactions.
\end{abstract}




\section{INTRODUCTION}

Oxalate is formed and consumed in numerous biotic and abiotic processes and occurs in microto millimolar concentrations in soil porewater, DOC-rich surface waters, and in aerosols. In the pH range from 3 to 7 , oxalate adsorbs strongly to mineral oxide surfaces and affects the surface properties and the dissolution rates of minerals. Of particular importance is the role of oxalate in the dissolution of Fe-containing minerals, which influences the bio-availability of $\mathrm{Fe}$ in soils, surface water, and the ocean. Oxalate can promote the dissolution in non-reductive and reductive reactions (Banwart et al., 1989; Cheah et al., 2003; Kraemer, 2004; Loring et al., 2008; Reichard et al., 2007), and in light-induced reactions (Cwiertny et al., 2009; Deutsch et al., 2001; Sulzberger and Laubscher, 1995). The formation, structure and properties of oxalate surface complexes on iron(hydr)oxide phases are thus of continued interest.

Several studies have addressed the adsorption and the structure of oxalate surface complexes on metal (hydr)oxide (MHO) and specifically on iron(hydr)oxide mineral surfaces with spectroscopic methods, particularly with infrared (IR) spectroscopy. With the progress of computational methods, results of spectroscopic studies can be compared to computational results of increasingly realistic representations of MHO-surface sites with oxalate adsorbed in various possible structures, including the presence of water. A complicating factor is that measured infrared spectra are often the sum of contributions from several surface complexes. Most studies, both experimental and theoretical, agree that oxalate can form several different surfaces complexes on each investigated MHO. However, a consistent view on the adsorption mechanisms and the contributions of various complexes and their structures is still missing. Outer-sphere (OS), hydrogen-bonded outer-sphere (HOS), and several inner-sphere complexes, such as monodentate-mononuclear (MM), bidentatemononuclear (BM), bidentate-binuclear (BB), and differently protonated structures can contribute to observed spectra. In the following, we briefly review the findings of previous studies.

In one of the first studies applying Attenuated Total Reflectance Fourier Transform Infrared spectroscopy (ATR-FTIR) with metal-oxide coated ATR-elements, the adsorption of oxalate to $\mathrm{TiO}_{2}$ was studied as a function of concentration and $\mathrm{pH}$ (1-1000 $\mu \mathrm{M}$ oxalate, $\mathrm{pH}$ 2.9-8.6) (Hug and Sulzberger, 1994). It was found that several different surface complexes are formed as a function of aqueous concentration and $\mathrm{pH}$. The authors suggested that inner-sphere BM and/or BB structures and a protonated surface complex are formed, but a comparison with molecular orbital (MO) calculations could not be performed at that time. A series of subsequent ATR-FTIR studies addressing the adsorption of oxalate as function of $\mathrm{pH}$, concentration and time (without MO-calculations) found further evidence for the formation of several surface complexes. Degenhardt and McQuillan measured the $\mathrm{pH}$-dependence and kinetics of the adsorption of oxalate $(0-1 \mathrm{mM}$ oxalate, $\mathrm{pH} 3)$ on amorphous $\mathrm{Cr}(\mathrm{III})$ (hydr)oxide and suggested a fast formation of ionic (OS), and hydrogen-bonded oxalate (HOS), followed by a slower formation of coordinated oxalate with BM or BB structures (Degenhardt and McQuillan, 1999). They suggested that at low $\mathrm{pH}$, protonation and breaking of $\mathrm{Cr}-\mathrm{O}-$ $\mathrm{Cr}$ linkages could lead to more sorption sites, which could explain the slowly increasing contribution of the spectrum of coordinated oxalate. Later, Young and McQuillan followed the adsorption/desorption kinetics of oxalate at the $\mathrm{TiO}_{2}$ interface at $\mathrm{pH} 4.0$ with $100 \mu \mathrm{M}$ oxalate. An analysis of the desorption kinetics yielded three different rate constants, each corresponding to the desorption of a different surface complex (Young and McQuillan, 2009). The most slowly desorbing complex was the one with a spectral signature consistent with a BM or BB structure, the least stable was the OS complex. Hug and Bahnemann measured and compared IR-spectra of oxalate, malonate and succinate adsorbed on anatase, rutile and lepidocrocite, as a function of $\mathrm{pH}(3-9)$ at $200 \mu \mathrm{M}$ aqueous concentrations of the dicarboxylates (Hug and Bahnemann, 2006). The spectra of each ligand exhibited distinct differences on the different oxides. A qualitative interpretation of spectra lead to the conclusion that oxalate formed five or six-member chelate ring structures (BM or BB, respectively) involving one $\mathrm{O}$ from each carboxylic group and that multiple complexes were formed at each surface. Loring et al. followed the adsorption of oxalate [ca. $1 \mu \mathrm{mol} / \mathrm{m}^{2}$ ] with ATR-FTIR over a timescale of days (Loring et al., 2008). They observed initial formation of outer- and inner-sphere 
surfaces complexes, followed by formation of a pool of tris-oxalate that remained adsorbed on the surface at $\mathrm{pH} 4$, and which was then quickly dissolved upon addition of deferrioxamine (DFOB). It was suggested that OS and BM surface complexes are formed quickly, followed by slow formation of adsorbed Fe(III)-tris-oxalato complexes. Simanova et al. measured the formation of oxalate surface complexes on goethite at $\mathrm{pH} 4$ on a time scale from minutes to 2 days with an oxalate surface concentration of $1 \mu \mathrm{mol} / \mathrm{m}^{2}$ (Simanova et al., 2011). The temporal evolution of the IR-spectra was explained with four coordination modes of oxalate: OS, HOS, BM, and inner-sphere with ternary-type complex (BM adsorption to Fe(III) adsorbed to the surface). Situm et al. studied the adsorption of citrate, oxalate and pyrocatechol on hematite nanoparticles with ATR-FTIR and found that oxalate formed deprotonated outer-sphere complexes with contributions from deprotonated inner-sphere complexes (Situm et al., 2016).

A group of more recent studies applied MO-calculations to interpret experimentally measured spectra. Persson and Axe investigated the adsorption of oxalate and malonate on goethite $(0.7$ and $1.4 \mu \mathrm{mol} / \mathrm{m}^{2}$ oxalate, $\mathrm{pH} 2.5-8$ ) (Persson and Axe, 2005) and suggested that oxalate and malonate form HOS and inner-sphere BM surface complexes on goethite. By comparing the IR-spectra of adsorbed oxalate to spectra of dissolved Fe-oxalate and to calculated IR-spectra (DFT using B3LYP functionals, standard $6-31+G$ basis set and Gaussian 98 ), they suggested that the surface complexes are five-membered ring BM structures. Mendive et al. studied oxalate complexes on the surface of rutile and anatase and compared experimental ATR-FTIR spectra (100-400 $\mu \mathrm{M}, \mathrm{pH}$ 3.7) with theoretical predictions of semi-empirical (MSINDO) calculations (Mendive et al., 2009). These authors found evidence for three different surface complexes on rutile and four complexes on anatase and suggested that bidentate complexes are more stable than monodentate complexes. Bhandari et al. studied the adsorption of oxalate on ferrihydrite $(\mathrm{FH})$ and the photodissolution of $\mathrm{FH}$ upon irradiation with light from a high-pressure xenon lamp (Bhandari et al., 2010). IR-spectra were measured at pH 4.5 and with $5 \mathrm{mM}$ aqueous oxalate concentrations. Adsorption from 0-30 min showed an evolution to a final spectrum, from which the following peak positions were determined: $1708 \mathrm{~cm}^{-1}\left[\mathrm{v}_{\mathrm{s}}(\mathrm{C}=\mathrm{O})\right]$, $1668 \mathrm{~cm}^{-1}\left[\mathrm{v}_{\mathrm{a}}(\mathrm{C}=\mathrm{O})\right], 1412 \mathrm{~cm}^{-1}\left[\mathrm{v}_{\mathrm{s}}(\mathrm{C}-\mathrm{O})\right.$ and $\mathrm{v}(\mathrm{C}-\mathrm{C})$ combination mode] and $1280 \mathrm{~cm}^{-1}\left[\mathrm{v}_{\mathrm{a}}(\mathrm{C}-\mathrm{O})\right]$. The structure of adsorbed oxalate was derived by comparison of measured spectra with frequencies obtained from DFT-calculations (Gaussian 03E.0126 at the B3LYP/6-31G level). They concluded that a BM structure was most likely, while an MM structure showed a slightly worse agreement with the experimental peak positions. Their spectra are in agreement with the observations and interpretations of Hug and Bahnemann (Hug and Bahnemann, 2006),.

In summary, all previous studies concluded that oxalate forms more than one surface complex structure at the investigated MHO surfaces and that the inner-sphere complexes are BM or BB structures. However, a convincing separation of experimentally observed spectral contributions into spectra of different surface complexes and their comparison with calculated spectra is still missing.

The aim of this study was the separation of spectra from different surface complexes and the determination of their structure by comparison with calculated spectra A second aim was to assess the reactivity of the different surface complexes. We thus investigated the adsorption of oxalate to lepidocrocite in more detail by comprehensive measurements, in combination with state-of-the art density function theory (DFT) calculations with solvated periodic structures and representative molecular clusters. Lepidocrocite ( $\gamma$ - $\mathrm{FeOOH}$, space group Pnma) was chosen for its importance in various aqueous environments and its higher reactivity in dissolution reactions compared to hematite and goethite. A detailed knowledge about the $\mathrm{pH}$-dependent formation and structure of surface complexes of oxalate is a prerequisite for the understanding of the effects of oxalate on the dissolution of iron oxides. IR-spectra contain detailed structural information, but the separation of observed spectral contributions into spectra of different surface complexes and their structural interpretation is challenging. Adsorption and photochemical experiments were designed to allow for a separation of different spectral contributions and to find the most consistent agreement between separated measured and calculated spectra. To derive more generally valid conclusions for lepidocrocite, we conducted experiments with two morphologically different samples of synthetic lepidocrocite. 


\section{MATERIALS AND METHODS}

\subsection{Materials}

Two types of lepidocrocite were used, in the following abbreviated with Lp-1 and Lp-2. Lp-1 was synthesized according the method of Brauer (1963), as described in detail in Borer et al. (Borer et al., 2009) and had a specific surface area of $130 \mathrm{~m}^{2} / \mathrm{g}$ (determined by the multipoint $\mathrm{N}_{2}$-BrunauerEmmett-Teller (BET) method. Lp-2 was synthesized according to the method of Schwertmann et al. (Schwertmann and Cornell, 2000) and had a specific BET surface area of $63 \mathrm{~m}^{2} / \mathrm{g}$. Purity and crystallinity was confirmed by X-ray powder diffraction analysis. Oxalic acid dihydrate $\left(\mathrm{C}_{2} \mathrm{H}_{2} \mathrm{O}_{4} \cdot 2 \mathrm{H}_{2} \mathrm{O}\right.$, Sigma-Aldrich, > 99\%), sodium chloride ( $\mathrm{NaCl}$, Merck, > 99\%), piperazine-1,4-bis-(propane-sulfonic acid) (PIPPS, $\mathrm{C}_{10} \mathrm{H}_{22} \mathrm{~N}_{2} \mathrm{O}_{6} \mathrm{~S}_{2}, \mathrm{pK}_{\mathrm{a}}=3.73$, Merck), 1,4-dimethylpiperazine (DEPP, $\mathrm{C}_{6} \mathrm{H}_{14} \mathrm{~N}_{2}, \mathrm{pK}_{\mathrm{a}}=4.48$, Sigma-Aldrich, >98\%), 2-morpholinoethanesulfonic acid monohydrate (MES, $\mathrm{C}_{6} \mathrm{H}_{13} \mathrm{NO}_{4} \mathrm{~S} \cdot \mathrm{H}_{2} \mathrm{O}, \mathrm{pK}_{\mathrm{a}}=$ 6.06 , Merck, $>99 \%$ ) were used as received without further purification. Ultrapure water (resistivity $>$ 18.2 $\mathrm{M} \Omega \cdot \mathrm{cm}, \mathrm{TOC}>2 \mathrm{ppb}$, Milli-Q, Millipore) was used in all experiments.

\subsection{FTIR Measurements}

Infrared spectra (4000-400 $\mathrm{cm}^{-1}, 2 \mathrm{~cm}^{-1}$ resolution, 32 or 64 scans) were recorded on a Biorad FTS $575 \mathrm{C}$ instrument equipped with a mercury cadmium telluride (MCT) detector and a 9-reflection ATR unit (SensIR Technologies, Danbury, CT), as described in detail previously (Borer and Hug, 2014; Borer et al., 2007; Borer et al., 2009). In brief, the circular (4 mm diameter) diamond surface of the ATRunit was coated with 15-30 $\mu$ g lepidocrocite (both for $L p-1$ and $L p-2$ ). Subsequently a liquid cell assembly was mounted on the ATR-plate and the layer was immersed in aqueous solution (10-40 ml of $10 \mathrm{mM} \mathrm{NaCl}$ inert electrolyte). Once the signal was stable, a single beam spectrum was recorded, which served as the background for the calculation of subsequent absorbance spectra. The liquid was purged with $\mathrm{N}_{2}$, which lead to desorption of adsorbed $\mathrm{CO}_{2}$. (Spectra of a lepidocrocite layer and difference spectra during desorption of $\mathrm{CO}_{2}$ are shown in Figures EA1A and EA1B). A new background spectrum was measured after the signal was stable, before $200 \mu \mathrm{M}$ oxalate was added. Adsorption kinetics and $\mathrm{pH}$-dependent spectra were measured by changing and adjusting the $\mathrm{pH}$ with $0.1 \mathrm{M} \mathrm{HCl}$ and $\mathrm{NaOH}$. The spectra of dissolved oxalic acid and oxalate were measured by titrating a $50 \mathrm{mM}$ oxalic acid solution in contact with the uncoated ATR-diamond surface with $1 \mathrm{M} \mathrm{NaOH}$ (the background single beam spectrum was that of pure $\mathrm{H}_{2} \mathrm{O}$ ). These spectra were corrected for the slight dilution by addition of $\mathrm{NaOH}$. Spectra of Fe-oxalate complexes were measured with 1:1, 1:2 and 1:3 mixtures of $\mathrm{FeCl}_{3}$ and oxalate $\left(10 \mathrm{mM} \mathrm{FeCl}_{3}\right.$ and $10-30 \mathrm{mM}$ oxalate in $\mathrm{H}_{2} \mathrm{O}$ and $50 \mathrm{mM} \mathrm{FeCl}_{3}$ and 50 $\mathrm{mM}$ oxalate in $\mathrm{D}_{2} \mathrm{O}$, respectively). Photochemical experiments were conducted with $1.0 \mathrm{ml}$ of $200 \mu \mathrm{M}$ $\mathrm{pH} 4.0$ oxalate solution, covered with a UV-transparent glass plate. After a stable adsorption plateau had been reached $(30 \mathrm{~min}$ ), the lepidocrocite layer was illuminated with a UV-LED lamp (Dr. Groebel UVElektronik $\mathrm{GmbH}$, Ettlingen, Germany, $365 \pm 5 \mathrm{~nm}$ ) at $3.25 \mathrm{~cm}$ distance above the layer. The photon flux, measured by ferrioxalate actinometry, was $2 \pm-0.3 \mu \mathrm{mol}$ photons/min (corresponding to $960 \mathrm{~W} / \mathrm{m}^{2}$ ) at the oxide layer, approximately 9-fold the irradiance of natural sunlight in the range of 300-450 nm. For more details see (Borer and Hug, 2014). In all FTIR non-photochemical experiments described here, oxalate in solution $(40 \mathrm{ml}$ of $200 \mu \mathrm{M}=8.0 \mu \mathrm{Mol})$ was in large excess over lepidocrocite (30ug) available surface sites (e.g. $15.7 \mathrm{nMol}$ surface sites for Lp-2, assuming 5 sites $/ \mathrm{nm}^{2}$ ). Thus, oxalate concentrations did not change during the experiments and the oxalate surface concentrations were those in equilibrium with $200 \mu \mathrm{M}$ aqueous oxalate. This concentration can occur in soils and atmospheric water, does not lead to an untypical oversaturation of the surface, and is in the range of previously conducted and published studies. 


\subsection{Dissolution and adsorption experiments}

\subsubsection{Oxalate promoted dissolution of lepidocrocite}

The dissolution of $\mathbf{L p}-\mathbf{2}$ was observed under ambient air at constant temperature $\left(20 \pm 1^{\circ} \mathrm{C}\right)$. All experiments were performed in $100 \mathrm{~mL}$ LDPE reactors. The reactors were wrapped in aluminum foil to prevent potential photo-reductive reactions. The lepidocrocite suspensions were completely mixed with a magnetic stirrer and a Teflon-coated stirring bar. The ionic strength was fixed with 0.01 $\mathrm{M} \mathrm{NaCl}$. The $\mathrm{pH}$ was adjusted with $\mathrm{HCl}$ or $\mathrm{NaOH}$ solutions and buffered at $\mathrm{pH}$ values between 4 and 6 $( \pm 0.05)$ with $0.005 \mathrm{M}$ of PIPPS (pH 4 and 4.5), DEPP (pH 5 and 5.5) or MES (pH 6). Lepidocrocite suspensions were equilibrated overnight prior to oxalate addition at $90 \%$ of the final solution volume in ambient air. Oxalate was added to a concentration of $500 \mu \mathrm{M}$ and the lepidocrocite suspensions density was set to $0.1 \mathrm{~g} \mathrm{~L}^{-1}$. Suspension samples were taken periodically and filtered over $0.1 \mu \mathrm{m}$ pore sized polyvinylidene fluoride (PDVF) syringe filter (SLVV033RS, Merck). Sampling frequency depended on the $\mathrm{pH}$. Samples were acidified with trace metal grade nitric acid (Fisher) and the total dissolved Fe concentration was determined by inductively coupled plasma mass spectrometry (ICP-MS, Agilent 7700).

\subsubsection{Adsorption of oxalate on lepidocrocite}

Adsorption experiments with oxalate and $1 \mathrm{~g} \mathrm{~L}^{-1} \mathbf{L p}-\mathbf{2}$ were conducted for the $\mathrm{pH}$ range $\mathrm{pH} 4$ to $\mathrm{pH} 6$ at an ionic strength corresponding to the dissolution experiments. The suspension $\mathrm{pH}$ values were set using $\mathrm{HNO}_{3}$ and $\mathrm{NaOH}$ solutions and the suspensions were equilibrated overnight prior to oxalate addition at $90 \%$ of the final solution volume in ambient air. Oxalate was added to the lepidocrocite suspension to a concentration of $500 \mu \mathrm{M}$ and equilibrated for $1 \mathrm{~min}$. In order to prevent a $\mathrm{pH}$ drift due to co-adsorption of protons to the lepidocrocite surface, $\mathrm{HNO}_{3}$ solution was added, and the suspension $\mathrm{pH}$ were stable during the reaction time $( \pm 0.05)$. The interaction time was set to minimize lepidocrocite dissolution, but still approach adsorption equilibrium. The total dissolved iron concentrations after the interaction time were measured by ICP-MS. Dissolved iron as iron-oxalate complexes accounted for less than 2 percent of the applied amount of oxalate. We expect that adsorption of iron-oxalate complexes is minimal under these conditions, but in the absence of adsorption measurements for such complexes their effect on oxalate surface speciation is not known. Samples were filtered over $0.1 \mu \mathrm{m}$ pore sized PDVF syringe filter (SLVV033RS, Merck (0.1 $\mu \mathrm{m})$. The total dissolved oxalate concentration was analyzed by High-performance liquid chromatography (HPLC, Agilent 1260) using a ZORBAX SB-C18 $(4.6 \times 150 \mathrm{~mm}, 5 \mu \mathrm{m})$ column. A diode array detector (BIO Max-Light Cell $10 \mathrm{~mm}, \mathrm{G} 5615-60018, \lambda=210 \mathrm{~nm}$ ) was connected to the HPLC. The mobile phase was composed of acetonitrile $\left(\mathrm{CH}_{3} \mathrm{CN}\right.$, Merck, $\left.>99.5 \%\right)$ and water in a ratio of 50:50;

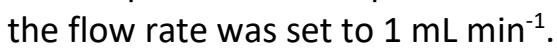

\subsection{Computational methods}

\subsubsection{Model Construction}

Periodic cells: Using Materials Studio 6.0,(Accelrys Software, 2007) models of the oxalatelepidocrocite-water system were created by cleaving the respective surfaces - $(010)$ and (100) - from the experimental crystal structure of bulk lepidocrocite (space group Pnma) through the plane breaking the fewest number of $\mathrm{Fe}-\mathrm{O}$ bonds. Periodic models of the surfaces were created with a vacuum space of $20 \AA$ between repeating lepidocrocite surfaces. Oxalate was added to the surface in both monodentate and bidentate configurations as guided by previous results on molecular clusters (Bhandari et al., 2010). Outer-sphere configurations were created with $\mathrm{C}_{2} \mathrm{O}_{4}{ }^{2-}$. In order to mimic a "dry" surface, 36 and $32 \mathrm{H}_{2} \mathrm{O}$ molecules were added to the (010) and (100) models, respectively. To mimic a "solvated" surface, 125 and $95 \mathrm{H}_{2} \mathrm{O}$ molecules were added to the (010) and (100) models, respectively, representing a density of approximately $1 \mathrm{~g} / \mathrm{cm}^{3}$. For the dry systems, two $\mathrm{H}^{+}$ions were added to random bi-coordinated $\mathrm{O}$ atoms of the lepidocrocite slabs to maintain an electrostatically 
neutral simulation cell. For the solvated systems, two $\mathrm{H}^{+}$ions were added to random $\mathrm{H}_{2} \mathrm{O}$ molecules. The mineral slab of the periodic systems studied for the (010) system consisted of $\mathrm{Fe}_{64} \mathrm{O}_{128} \mathrm{H}_{64}$, measuring $15.5 \times 12.3 \times 32.0 \AA^{3}$, and the (100) system consisted of $\mathrm{Fe}_{48} \mathrm{O}_{120} \mathrm{H}_{96}$ measuring $12.7 \times$ $11.8 \times 30.8 \AA^{3}$. The magnetic ordering of the Fe atoms was set according to the experimentallyobserved antiferromagnetic pattern (Coey et al., 1995; Cornell and Schwertmann, 2003) as described previously (Kubicki et al., 2008).

Molecular clusters: Upon completion of the energy minimizations of the periodic systems, molecular clusters were extracted. Each cluster was created by selecting the third nearest neighbors of the surface atoms bonded to the adsorbed oxalate, then expanded until eight Fe atoms were included. The Fe atoms were terminated with $\mathrm{OH}^{-}$and $\mathrm{H}_{2} \mathrm{O}$ groups, eliminating dangling bonds and maintaining overall charge neutrality. Additional $\mathrm{H}_{2} \mathrm{O}$ molecules were added to hydrogen bond to the oxalate, yielding $\mathrm{Fe}_{8} \mathrm{O}_{42} \mathrm{H}_{54} \mathrm{C}_{2}$ clusters (exceptions noted).

\subsubsection{Calculations with periodic cells}

Projector-augmented plane-wave calculations (Blöch, 1994; Kresse and Joubert, 1999) were performed using VASP 5.2, (Kresse and Furthmüller, 1996) using the generalized gradient approximation (GGA) PBE pseudopotentials (Perdew et al., 1997; Perdew et al., 1996) and Vanderbilt-type ultrasoft pseudopotentials (Laasonen et al., 1991) with an energy cutoff of $500 \mathrm{eV}$. The electron density cutoff was $1 \times 10^{-4} \mathrm{eV}$. Partial occupancies were determined using the firstorder scheme of the Methfessel-Paxton method with a $0.1 \mathrm{eV}$ width. Initial magnetic moments of Fe atoms were assigned as alternate positive and negative values $( \pm 5)$ on the crystalline layers along the Miller direction [010] so as to obtain an antiferromagnetic lepidocrocite slab in each case. The on-site Coulomb interaction, the GGA+U method, was applied to the Fe atoms according to the approach of Dudarev et al. as implemented in VASP (Dudarev et al., 1998). The supercell lattice parameters were held fixed throughout the simulations, but all atoms were allowed to relax without symmetry restrictions. A single $k$-point was evaluated at the $\Gamma$-point of the supercell, which provides acceptable energy results for such relatively large models. Each model was energy minimized; the ionic relaxations were considered to be converged when the change in the free energy of the system between two steps dropped below $1 \times 10^{-2} \mathrm{eV} \AA^{-1}$.

\subsubsection{Calculations with molecular clusters}

Energy minimizations were performed in the gas-phase using Gaussian 09 (Frisch et al.) with all Fe atoms initially frozen and then allowed to relax. This stepwise energy minimization helps to ensure that the cluster model retains structural similarity to the original periodic surface configuration. Only high-spin complexes were analyzed. The B3LYP exchange-correlation functional (Becke, 1993; Lee et al., 1988) was used with the 6-31G(d,p) basis set (Rassolov et al., 2001). Upon completion of the energy minimizations, frequency calculations were conducted (with no imaginary frequencies in the final geometries). The model harmonic frequencies were scaled by 0.961 before comparing with observation to account for anharmonicity, basis set effects, and approximations in electron correlation. (Note that this is an approximate scaling factor based on the Scott and Radom value for B3LYP/6-31G(d) of 0.9614 (Scott and L, 1996).) To determine if there was a significant difference in the geometry or analytical frequencies, one cluster was optimized with and without implicit solvation, using a polarized continuum model (IEFPCM (Cancès et al., 1997) Solvent=Water). No significant differences were found in the geometry of the bound oxalate; however, there were differences in the frequencies (Table EA1). As the correlation of the theoretical frequencies to experiment was slightly worse when the PCM method was employed, and the computational time was markedly increased, the PCM method was not used (exceptions noted). As a check, one of the complexes was optimized employing the $\mathrm{PCM}=$ (water), but no significant changes were observed in either the geometry or energies of the frequencies. Vibrations were visualized with Chemcraft (https://www.chemcraftprog.com) and figures of complexes were made with VMD (Humphrey et al., 1996). 


\section{RESULTS}

\subsection{Characterization and properties of lepidocrocite samples}

Transmission electron microscopy (TEM) images of the two lepidocrocite samples are shown in Figure 1. Lp-1 consisted of hedge-hog shaped spherical agglomerations (200-400 nm in diameter) of lath-like, very thin irregularly shaped sheets of 20-100 nm length width and less than $20 \mathrm{~nm}$ thickness (Figure $1 \mathrm{~A}$ ). The predominating surfaces of ideally crystallized sheets are the (010) surfaces. Lp-2 consisted of plate-like (50-100 nm width and 200-500 nm width) agglomerations of 200-500 long rods of $10 \mathrm{~nm}$ width and less than $10 \mathrm{~nm}$ thickness (Figure 1B). The predominating surfaces are (010) and (100), with lower contributions of (001) (Figure 1C) and other surfaces (not shown). The ideally crystallized (010) surface contains only "proton and ion-exchange inactive," doubly coordinated surface hydroxyl groups ( $\equiv \mathrm{Fe}_{2}-\mathrm{OH} ; \mu-\mathrm{OH}$ sites) that would not be expected to exchange with oxalate. The (100) surfaces contain two rows of "active" singly coordinated -OH groups (=Fe-OH sites) and on row of "inactive", triply coordinated ( $\equiv \mathrm{Fe}_{3}-\mathrm{OH} ; \mu_{2}-\mathrm{OH}$ sites). The (001) surface contains an equal numbers of singly and doubly coordinated hydroxyl groups. With ideal surfaces, we would expect a higher density of adsorption active sites on the rod-shaped Lp-2 (compared to the lath-shaped Lp-1 with mostly inactive 010 surfaces), despite of its lower specific surface area, and possibly observable differences in the spectra of oxalate adsorbed to the different samples. However, the 010 faces of lepidocrocite typically contain a large number of defect sites with also "active" singly coordinated $-\mathrm{OH}$ groups. It is suspected that the amount of defect sites associated with (010) surfaces of Lp-1 and -2 will lead to similar reactivities. For example, it was found that differences in lepidocrocite particle morphology or roughness did not significantly impact surface charge development (Hiemstra and van Riemsdijk, 2007).

\subsection{ATR-FTIR spectra of oxalate in aqueous solution and adsorbed to lepidocrocite}

The spectra of oxalate show distinct changes upon protonation and complexation to metal ions. The dissolved oxalate dianion with staggered $D_{2 d}$ or planar $D_{2 h}$ geometry has four equivalent $C-O$ bonds and exhibits two strong infrared peaks in the range from $1300-1600 \mathrm{~cm}^{-1}$. The symmetry is lowered with protonation and complexation, and new bands with predominantly $\mathrm{v}(\mathrm{C}=\mathrm{O})$ character at high energy and mainly $v(\mathrm{C}-\mathrm{O})$ character at lower energy appear. In solution or surface complexes with BM structures in which oxalate has a close to $C_{2 v}$ symmetry, peaks in the $1690-1715 \mathrm{~cm}^{-1}$ and 1660 $1690 \mathrm{~cm}^{-1}$ ranges, were assigned to symmetric $v_{s}(C=0)$ and asymmetric $v_{a s}(C=O)$ coupled vibrations, and two strong peaks at $1390-1430 \mathrm{~cm}^{-1}$ and $1270-1320 \mathrm{~cm}^{-1}$ to $v_{s}(C-O)+v(C-C)$ and to $v_{\text {as }}(\mathrm{C}-\mathrm{O})$ stretching vibrations (Bhandari et al., 2010). Oxalate surface complexes as modeled here with complex clusters including surrounding water molecules, can deviate from $\mathrm{C}_{2 v}$ symmetry and the assignment of vibrations might thus change.

\subsubsection{Spectra of aqueous oxalate species}

Figure $2 \mathrm{~A}$ shows the $\mathrm{pH}$-dependent spectra of oxalate in aqueous solution. Oxalic acid has a $\mathrm{p} K_{\mathrm{a}_{1}}$ of $0.97-1.26$ and a $\mathrm{p}_{\mathrm{a}_{2}}$ of 3.57-4.27, depending on the ionic strength (Axe and Persson, 2001; Yoon et al., 2004). In the IR spectrum of oxalic acid at pH 1.36, both the neutral and anionic species are seen in solution. As the $\mathrm{pH}$ is increased, the dianionic species becomes dominant; by $\mathrm{pH} 5.40$ only the dianionic species, $\mathrm{C}_{2} \mathrm{O}_{4}{ }^{2-}$, is seen. In the IR spectra of the dianion, two asymmetric $\left[\mathrm{v}_{\mathrm{a}}(\mathrm{C}-\mathrm{O})\right]$ stretches are seen at $1308 \mathrm{~cm}^{-1}$ and $1566 \mathrm{~cm}^{-1}$, respectively. Using Raman spectroscopy, an additional symmetric $[\mathrm{vs}(\mathrm{C}-\mathrm{O}) \mathrm{p}(\mathrm{C}-\mathrm{C})]$ stretch is seen at $1456 \mathrm{~cm}^{-1}$ (Begun and Fletcher, 1963; Hind et al., 1998). 


\subsubsection{Spectra of oxalate adsorbed to $L p-1$ and $L p$-2 as a function of time and $p H$}

Figures $2 \mathrm{~B}$ and $2 \mathrm{C}$ show the spectra of adsorbed oxalate on $\mathbf{L p}-\mathbf{1}$ and $\mathbf{L p}-\mathbf{2}$, respectively, at different $\mathrm{pH}$-values. The $\mathrm{pH}$-values were decreased in rapid steps by addition of dilute $\mathrm{HCl}$. Shown, are the spectra collected 30-40 min after each $\mathrm{pH}$ change, at which time the spectral amplitudes did not change by more than $1-2 \%$ in one minute. The amplitudes of several characteristic peaks as a function of time for $\mathbf{L p}-\mathbf{2}$ are shown in Figure 2D. As the $\mathrm{pH}$ is lowered, increasing absorbances in the three ranges from (1) $1250-1320 \mathrm{~cm}^{-1}$, (2) $1380-1470 \mathrm{~cm}^{-1}$, and (3) $1560-1720 \mathrm{~cm}^{-1}$ are observed. Vibrations in the first two ranges are assigned to $\mathrm{C}-\mathrm{O}$ stretches, while vibrations in the latter region are likely $\mathrm{C}=\mathrm{O}$ stretches.

The peak-positions of adsorbed oxalate and the spectral changes with $\mathrm{pH}$ on $\mathbf{L p}-\mathbf{1}$ and on $\mathbf{L p}$ 2 are almost identical. Also observed on both samples, is the larger increase of the $1710-1711 \mathrm{~cm}^{-1}$ peak relative to the $1624-1625 \mathrm{~cm}^{-1}$ peaks when lowering the $\mathrm{pH}$. The spectra of adsorbed oxalate measured on Lp-2 shows slightly more distinct features than on Lp-1. For example, the peaks at $1624,1565,1436$, and $1309 \mathrm{~cm}^{-1}$ are more defined for $\mathbf{L p}-\mathbf{2}$ than the corresponding shoulders at closely the same positions for $\mathbf{L p}-\mathbf{1}$. The largest difference of the spectra on $\mathbf{L p}-\mathbf{2}$ compared to $\mathbf{L p}-\mathbf{1}$ is the higher amplitude of the two peaks at 1565 and $1309 \mathrm{~cm}^{-1}$, which correspond closely to the peaks of aqueous oxalate. For a comparison, Figure EA1E shows additional spectra of oxalate on Lp-1 which were recorded with a slow adjustment of the $\mathrm{pH}$ to pre-set values by computer-controlled titrators (adapted, with data from (Hug and Bahnemann, 2006)). Due to slow pH-adjustment, these spectra were equilibrated for longer times and did not change more than $1 \%$ on a time scale of $10-20$ minutes. The three data sets show the same spectral changes with $\mathrm{pH}$ : The peak positions and spectral changes for $\mathbf{L p} \mathbf{- 1}$ and $\mathbf{L p}-\mathbf{2}$ were very similar and are clearly more complex than a simple increase of all peak amplitudes with decreasing $\mathrm{pH}$. Most notably, the absorbance at $1710-1711 \mathrm{~cm}^{-1}$ shows the largest increase upon lowering the $\mathrm{pH}$, while the absorbance increases less at 1685 and $1575 \mathrm{~cm}^{-1}$ and slightly decreases at $1565 \mathrm{~cm}^{-1}$ from pH 4.0 to 3.0. The plot of peak amplitudes against time (Figure 2D) also shows different kinetics at different wavelengths. For example, the amplitudes at $1309 \mathrm{~cm}^{-1}$ and $1565 \mathrm{~cm}^{-1}$ reach an equilibrium value at pH 6 much faster than the amplitudes at other peak positions. The different responses in time and with $\mathrm{pH}$ at different wavelengths are a clear indication that several surface complexes form at different rates, and that their relative contributions are $\mathrm{pH}$-dependent.

\subsubsection{Spectrum of oxalate on $\mathrm{Lp}-2$ in $\mathrm{D}_{2} \mathrm{O}$}

To explore the role of hydrogen bonding, the adsorption experiment was also conducted in $\mathrm{D}_{2} \mathrm{O}$ (Figure $2 \mathrm{E}$ ). In $\mathrm{D}_{2} \mathrm{O}$, all bands were still quite broad, with only small differences in peak positions and with the same spectral changes upon lowering the pD. Three defined peaks were evident at 1707, 1681 , and $1631 \mathrm{~cm}^{-1}$ and were slightly more distinct than in $\mathrm{H}_{2} \mathrm{O}$. The broadness of the low-energy shoulder is reduced compared to the spectra on Lp-1 in Figure 2B, but the positions of all welldefined peaks are very similar and do not deviate by more than $5 \mathrm{~cm}^{-1}$. That there are only minor changes between the spectra in $\mathrm{H}_{2} \mathrm{O}$ and $\mathrm{D}_{2} \mathrm{O}$ suggest that the main features of spectra of surface complexes of oxalate on lepidocrocite are not strongly affected by hydrogen bonding.

\subsubsection{Spectra of dissolved Fe-oxalate complexes in $\mathrm{H}_{2} \mathrm{O}$ and $\mathrm{D}_{2} \mathrm{O}$}

The spectra of dissolved FeOx ${ }^{+}$(Figure $2 \mathrm{~F}$ ) in $\mathrm{H}_{2} \mathrm{O}$ and $\mathrm{D}_{2} \mathrm{O}$ show peaks at $1712,1691,1390$ and 1250 $\mathrm{cm}^{-1}$, similar to the positions of adsorbed oxalate, but the broad absorbances between 1565-1680 $\mathrm{cm}^{-1}$ and $1400-1450 \mathrm{~cm}^{-1}$ of adsorbed oxalate are largely absent. If the spectrum of adsorbed oxalate with a $\mathrm{BM}$ structure is expected to be similar to that of dissolved $\mathrm{FeOx}^{+}$, then the additional features visible in Figures $2 \mathrm{~B}-\mathrm{E}$ would indicate the presence of additional surface complexes with different structures. The spectra of $\mathrm{Fe}(\mathrm{Ox})_{2}{ }^{-}$and $\mathrm{Fe}(\mathrm{Ox})_{3}{ }^{3-}$ are similar, but the peak position at $1691 \mathrm{~cm}^{-1}$ in $\mathrm{FeOx}{ }^{+}$shifts to $1679 \mathrm{~cm}^{-1}$ and the amplitude increases. Since $\mathrm{Fe}(\mathrm{Ox})_{2}{ }^{-}$and $\mathrm{Fe}(\mathrm{Ox})_{3}{ }^{3-}$ structures are not possible on the surface, the relevant comparison is the $\mathrm{FeOx}^{+}$aqueous complex with similar amplitudes for the 1712 and $1691 \mathrm{~cm}^{-1}$ bands. This strengthens the evidence for an additional species with a different structure in the spectra of adsorbed oxalate. 


\subsection{Reactivity of adsorbed oxalate}

\subsubsection{Oxalate promoted dissolution rates and adsorption $\mathrm{pH}$-edge}

The surface concentration of oxalate on $\mathbf{L} \mathbf{p}-\mathbf{2}$ and the reactivity of adsorbed oxalate on ligand controlled dissolution (total oxalate concentration $=500 \mu \mathrm{M}$ ) are shown in Figure 3. The rate coefficients of ligand controlled dissolution $\mathrm{k}_{\llcorner}$have been calculated by rearrangement of the rate law for ligand controlled dissolution with $k_{L}=R_{L} /[L]_{a d s}$, where $R_{L}$ is the dissolution rate coefficient and $[L]_{\text {ads }}$ is the surface loading of oxalate. The corresponding data of Fe vs. time is shown in Figure EA2. Decreasing dissolution rate coefficients with increasing $\mathrm{pH}$ are indicative of changes in the surface speciation of the adsorbed ligand with a decreasing proportion of such species that serve as precursors of the rate- determining dissolution step. As will be shown in the discussion section, this observation is consistent with decreasing proportions of BM surface complexes and a shift towards less reactive $\mathrm{MM}$ and $\mathrm{OS}$ complexes with increasing $\mathrm{pH}$.

\subsubsection{Photochemical reactivity}

In addition to differences of dissolution rates induced by different surface complexes, we expect different photochemical reactivities. Spectra collected during the adsorption of oxalate to Lp-1 (Figure 4A) and the effects of subsequent illumination with $365 \mathrm{~nm}$ light are shown in Figure 4 B-D. During each of two illumination periods of $180 \mathrm{~s}$, a fast temporary decrease of the oxalate absorbance is observed. The response is proportionally most pronounced at $1708 \mathrm{~cm}^{-1}(39 \%$ decrease) to a lesser degree $1679 \mathrm{~cm}^{-1}$ (17\% decrease) and much less at 1435, 1409, 1308 and 1276 $\mathrm{cm}^{-1}$ (less than $12 \%$ decrease). The difference spectra shown in Figure $4 \mathrm{C}$ and the corresponding amplitude changes in Figure $4 \mathrm{D}$ shows that the spectral features that decrease most strongly during irradiation resemble predominantly a spectrum similar to dissolved FeOx+.

\section{DISCUSSION}

The experimental results show that oxalate forms several surfaces complexes on the surface of lepidocrocite, with different adsorption kinetics and contributions depending on $\mathrm{pH}$. Dissolution and photochemical experiments additionally provide evidence for the presence of several surfaces complexes with different reactivities. In order to compare experimental and calculated spectra, a separation of the experimentally measured spectra into contributions of different surface complexes is required. In the following, we describe the separation of spectra and the assignment of structures by comparison of measured frequencies with the calculated frequencies for a range of possible structures.

\subsection{Separation of spectra from different surface complexes}

The minimum number of spectra needed for each data set was determined by Singular Value Decomposition (SVD). As shown in the Supporting information (SI) in Figures EA3 and EA4, the data sets with oxalate adsorbed on Lp-1 and $\mathbf{L p}-\mathbf{2}$ could be reproduced within signal-noise by a linear combination of 3-5 SVD-components. Three components provided an adequate fit, with only small improvements with 4 and 5 components. We thus work on the basis that three surface complexes with distinct spectra can provide a satisfactory explanation for our experimental observations. Since we have no model describing the quantitative contribution of each spectrum as a function of $\mathrm{pH}$ and time that would allow us to transform the orthogonal SVD components (with both positive and negative amplitudes) into physically meaningful spectra of surface complexes, further assumptions have to be made. Spectra of surface complexes can only have positive amplitudes and should consist of a sum of line shapes from individual vibrations, with frequencies that can be compared to calculated frequencies. As the peaks in our spectra are rather broad due to Doppler and proximity broadening they are best described by Gaussian (rather than by Lorentzian) line shapes. 
We thus searched for spectra of three different surface complexes consisting of Gaussian line shapes, guided by the observations of the measured spectra and the results from DFT calculations (explained in detail in the next section). The data in Figures 2B-E show spectral features (peaks at $1308-1311 \mathrm{~cm}^{-1}$ and $1565-1567 \mathrm{~cm}^{-1}$ ) that closely resemble the spectrum of aqueous $\mathrm{C}_{2} \mathrm{O}_{4}{ }^{2-}$, particularly at pH 5-7 and at early times. Based on the DFT calculations, we expect two peaks for dissolved oxalate and for outer-sphere adsorbed oxalate. Upon lowering of the $\mathrm{pH}$ to 4.5 , we observe increasing spectral contributions in the three ranges from $1250-1320 \mathrm{~cm}^{-1}, 1380-1470 \mathrm{~cm}^{-1}$ and 1560 $1720 \mathrm{~cm}^{-1}$, with relatively small contributions at $1700-1720 \mathrm{~cm}^{-1}$. From pH 4.5-3.0, all contributions except those resembling the aqueous $\mathrm{C}_{2} \mathrm{O}_{4}{ }^{2-}$ dianion further increase, but the increase is disproportionally stronger for the relatively sharp peak at $1707-1711 \mathrm{~cm}^{-1}$. These observations suggest the formation of an OS complex at early times and higher $\mathrm{pH}$, and the formation of two inner-sphere complexes at lower $\mathrm{pH}$. Based on interpretations of previous studies, the two consistently most prominent peaks at low pH at $1707-1711 \mathrm{~cm}^{-1}$ and $1681-1685 \mathrm{~cm}^{-1}$ and the peaks at $1404-1410 \mathrm{~cm}^{-1}$ and $1273-1275 \mathrm{~cm}^{-1}$ are due to the spectrum of BM or BB surface complex (Axe and Persson, 2001; Bhandari et al., 2010; Duckworth and Martin, 2001; Hug and Bahnemann, 2006; Hug and Sulzberger, 1994; Yoon et al., 2004). The calculations predict 5 observable peaks for a BM or a BB complex. The spectral contributions that are the most prominent at early times at pH 6 at 1674-1676 $\mathrm{cm}^{-1}, 1428-35 \mathrm{~cm}^{-1}$ and around $1250-80 \mathrm{~cm}^{-1}$ are due to a third, not yet assigned, spectrum. The calculations suggest the possible formation of a MM complex with 4 peaks in this region and a fifth peak overlapping with the peak of the BB complex. Based on the calculations, we thus expect that $5+4+2=11$ peaks with Gaussian line shapes should be able to adequately explain the spectra.

To test whether 11 Gaussians are sufficient, and to obtain preliminary information about possible peak locations, each measured spectrum was individually fit with 11 Gaussians, as shown in Figure EA5 for the spectrum of oxalate adsorbed to $\mathbf{L p}-\mathbf{1}$ at $\mathrm{pH}$ 4.0. Guided by the calculated spectra (discussed later), the Gaussians were tentatively grouped as belonging to a BM (red lines with 5 Gaussians), MM (blue lines with four Gaussians) and OS (green lines with two Gaussians). All other measured spectra could similarly be fit to within-signal-to-noise, with 11 Gaussians. The resulting peak positions are listed in Table EA2. Some vibrations shift slightly with $\mathrm{pH}$ changes (by an average of $\pm 2 \mathrm{~cm}^{-1}$ ), but the same number of Gaussian line shapes with similar peak maxima can explain all spectra. However, fits with 11 Gaussians for each measured spectrum separately allowed a change of relative amplitudes and peak-widths and do not yet provide three consistent spectra with fixed peak positions, widths and amplitudes. Consistent spectra for three surface complexes were found by linear combination fitting as described in the following.

\subsubsection{Fits of data sets with three spectra consisting of fixed Gaussian line shapes}

As explained above, assuming that each spectrum of three formed surface complexes ( $\mathrm{S}_{\mathrm{O}}, \mathrm{S}_{\mathrm{MM}}$ and $\mathrm{S}_{\mathrm{BM}}$ ) does not change strongly with $\mathrm{pH}$ or surface concentration, linear combinations of these spectra (here arranged as columns in matrix S) should be able to reproduce the measured data-sets (arranged as columns in matrix $\mathbf{M}$ ) in linear combinations as described by matrix $\mathbf{C}$ :

$$
\mathbf{M}=\mathbf{S} \cdot \mathbf{C}
$$

with the three spectra in $\mathbf{S}$ described by a sum Gaussian lineshapes ( $G)$ :

$$
\begin{aligned}
& S_{O S}=G_{11}\left(v_{11}, w_{11}, a_{11}=1\right)+G_{12}\left(v_{12}, w_{12}, a_{12}\right) \\
& S_{M M}=G_{21}\left(v_{21}, w_{22}, a_{21}=1\right)+G_{22}\left(v_{22}, w_{22}, a_{22}\right)+G_{23}\left(v_{23}, w_{23}, a_{23}\right)+G_{24}\left(v_{24}, w_{24}, a_{24}\right) \\
& S_{B M}=G_{31}\left(v_{31}, w_{31}, a_{31}=1\right)+G_{32}\left(v_{32}, w_{32}, a_{32}\right)+G_{33}\left(v_{32}, w_{32}, a_{32}\right)+G_{34}\left(v_{32}, w_{32}, a_{32}\right)+G_{35}\left(v_{35}, w_{35}, a_{35}\right)
\end{aligned}
$$

Where $\mathrm{G}_{\mathrm{ij}}\left(v_{\mathrm{ij}}, \mathrm{w}_{\mathrm{ij}}, \mathrm{a}_{\mathrm{ij}}\right)=\mathrm{a}_{\mathrm{ij}} \cdot \exp \left(-\left(\left(v-v_{\mathrm{ij}}\right) /\left(1.4142 \cdot \mathrm{w}_{\mathrm{ij}} / 2.3548\right)\right)^{2}\right)$

aij are the amplitudes, $v_{i j}$ the positions of the peak maxima and $w_{i j}$ the peak widths at half maximum.

The first amplitude (peak at the lowest wavelength) of each spectrum was fixed to 1.0. Fixing one 
amplitude for each spectrum is necessary to obtain fixed spectra for each surface complex, as their overall amplitudes (contributions) to the measured spectra are optimized with matrix $\mathbf{C}$, computed with Matlab from the pseudo-inverse of $\mathbf{S}$ :

$$
\mathbf{C}=\operatorname{pinv}(\mathbf{S}) * \mathbf{M}
$$

All other 30 parameters ( 8 amplitudes, 11 peak position and 11 widths) were adjustable. As initial parameters for the peak maxima and widths, we used the average of the parameters obtained from the Gaussian fits to the individual spectra, as listed in Table EA2. The parameters for the three fixed spectra were optimized with the Nelder-Simplex routine in Matlab, by minimizing the sum of squared differences (SSr) between the measured and the reproduce spectra:

$$
\mathbf{S S r}=\sum_{i} \sum_{j}\left(\mathbf{M}-\mathbf{S}^{*} \mathbf{C}\right)^{2}
$$

The results of a fit to the combined kinetics and pH-dependence on Lp-2 are shown in Figure 5 A1-A3. A1 shows the measured spectra, A2 the reproduced spectra offset by 0.03 units, and A3 the residuals (measured- reproduced spectra) offset by 0.6 units. The fit is not perfect (as expected), but the reproduced spectra capture the main features and changes of the measured spectra. The resulting separated spectra are shown in Figure $5 \mathrm{~B}$. The spectrum $\mathrm{S}_{\mathrm{os}}$ closely resembles the spectrum of the dissolved oxalate dianion (Figure $2 \mathrm{~A}$ ) and $\mathrm{S}_{\mathrm{BM}}$ resembles the spectrum of the dissolved $\mathrm{FeOx}^{+}$complex (Figure $2 \mathrm{~F}$ ), while $\mathrm{S}_{\mathrm{MM}}$ does not show similarity to any of the dissolved spectra. Figure $5 \mathrm{C}$ shows the contributions of the three spectra as a function of time and $\mathrm{pH}$. The spectrum Sos saturates quickly upon addition of oxalate at $\mathrm{pH} 5.9$, but its contribution decreases within the next 40 minutes in favor of $S_{M M}$ and $S_{B M}$. Upon lowering the $\mathrm{pH}$ to 3.0, the relative contributions of $S_{B M}$ increase while the relative contributions of $\mathrm{S}_{\mathrm{MM}}$ and particularly of Sos decrease. The results of fits to other data sets and the ranges and standard deviations for peak positions are shown in Figures EA6 and EA7 and listed in Table EA3. The shape of separated spectra and the peak positions show some variation, but the main characteristics of the separated spectra are consistent and the peak position of the main peaks agree to $\pm 2 \mathrm{~cm}^{-1}$ for the $1708-1711 \mathrm{~cm}^{-1}$ to $\pm 8 \mathrm{~cm}^{-1}$ for most other peaks. The most unreliable peak positions are the ones of BM complex around $1643( \pm 28) \mathrm{cm}^{-1}$ and of the MM complex around 1611 $( \pm 18) \mathrm{cm}^{-1}$. This is due to overlap of BM and MM peaks in this spectral regions and to lower signal-tonoise and background subtraction of the strong water peak of the electrolyte around $1630 \mathrm{~cm}^{-1}$. Despite the uncertainties, the separated spectra for BM complex consistently resembles the aqueous $\mathrm{FeOx}^{+}$complex and the spectra of the OS agrees very well with the spectrum of aqueous oxalate. The spectrum of the MM complex does not resemble any of the reference spectra, but its formation and the infrared frequencies in this range are predicted by the calculations. The mean values used for comparison with calculated frequencies and the standard deviations are listed in Table 1.

\subsection{DFT-calculations and identification of the structure of adsorbed complexes}

The adsorption of oxalate to two surfaces of lepidocrocite, (100) and (010), representing surfaces with either terminal or shared $\mathrm{OH}$ groups, were modeled, as shown in Figure 6. For the (100) surface, possible adsorption structures fall into four main categories: 1 ) the oxalate is bonded to a single Fe atom through one $\mathrm{O}$ atom, monodentate mononuclear (MM), 2) the oxalate is bonded to a single iron atom through two $\mathrm{O}$ atoms, bidentate mononuclear, either with two $\mathrm{O}$ atoms from the same carboxylic group (BM') or with one $\mathrm{O}$ atom of each carboxylic group (BM), 3) the oxalate is bonded to two Fe atoms through two $\mathrm{O}$ atoms, bidentate binuclear, again with $\mathrm{O}$ atoms from the same $\left(\mathrm{BB}^{\prime}\right)$ or from both carboxylic groups (BB and $\mathrm{BB}^{*}$ ). Because the hydroxyl groups on the $(010)$ surface are shared between two Fe atoms, bonding structures had to be slightly modified; the MM became a monodentate binuclear (MB), the $\mathrm{BB}^{\prime}$ a $\mathrm{BTetra}_{1}$, and the $\mathrm{BB}$ became either a bidentate tetranuclear $\left(\mathbf{B T e t r a}_{2}\right)$ or a bidentate trinuclear (BTri) structure. 4) Instead of replacing surface hydroxyl groups 
and forming direct bonds to surface Fe atoms, the oxalate could be hydrogen-bonded to hydroxyl groups attached to the Fe atoms, hydrogen-bonded outer sphere (HOS). This is not shown here, but discussed later.

\subsubsection{Calculation of adsorption energies with periodic structures (VASP)}

Calculations of the periodic cells were first carried out on energy-minimized structures of the periodic cells representing a "dry" surface. The energies of these models were used to determine the relative stability of various bonding configurations of oxalate (Table 2). The most stable configurations on the "dry" surfaces were found to be BTri on the (010) and BM on the (100) surface. More realistic adsorption energies ( $\Delta E_{\text {ads }}$ ) for aqueous systems were then calculated for "solvated" surfaces, as shown for $\mathbf{O S}, \mathbf{B M}$ and $\mathbf{M M}$ in Figure 7. The $\Delta E_{\text {ads }}$ of $\mathbf{B M}$ and $\mathbf{M M}$ on the (100) surface (Figure 7) were found to be -89 and $-98 \mathrm{kJmol}^{-1}$, respectively, whereas the $\Delta E_{\text {ads }}$ of $\mathbf{B T r i}$ on the (010) surface (structure not shown) was found to be $+29 \mathrm{kJmol}^{-1}$. The negative values favor adsorption and are similar to other calculated $\Delta E_{\text {ads }}$ of small organic and inorganic molecules to iron(hydr)oxide and other mineral surfaces (Gusain et al., 2016; Hansmann and Anderson, 1985; Kubicki, 2006; Kubicki et al., 2012; Mendive et al., 2009; Otte et al., 2013).

\subsubsection{Calculation of vibrational frequencies in representative molecular clusters (Gaussian)}

Calculating the vibrational frequencies of the periodic cells is computationally demanding and the numerical frequencies are not as accurate as analytical frequencies. Furthermore, IR intensities were not available through the periodic VASP calculations. Therefore, vibrational calculations were performed with molecular clusters extracted from the energy-minimized 100 and 010 surfaces. Validation of theoretical frequencies with dissolved oxalate species. To validate our methods, oxalic acid, the oxalate dianion, and trioxalatoiron(III) (Figure EA8) were energy-minimized and the analytical frequencies were obtained (B3LYP/6-31G(d,p)/PCM(water)) (Akutsu et al., 2004; Begun and Fletcher, 1963; Domagal-Goldman and Kubicki, 2008; Fujita et al., 1962a, b; Gouteron, 1976; Hind et al., 1998; Homborg and Preetz, 1976; Martin and Pinkerton, 1998; Öhrström and MichaudSoret, 1999; Persson and Axe, 2005; Shippey, 1980). The optimized structure of oxalic acid and trioxalatoiron(III) were compared to crystal structure data and found to be in excellent agreement (except for the FeO-C bond), suggesting that the intramolecular forces are being properly accounted 'for (Table EA4). A comparison involving oxalate was omitted; although the crystal structure is $D_{2 h}$ symmetry, in aqueous solution the dianion adopts a symmetry closer to $D_{2 d}$. (Hind et al., 1998) Based on slope, $R^{2}$, $y$-intercept, and standard deviation of error (Figure EA9, Table EA5), the calculated frequencies correlated well with observation (Table EA5). Trioxalatoiron(III) had an excellent correlation, whereas the correlation $\left(R^{2}\right)$ and the slope and intercept for oxalic acid was less accurate. It is hypothesized that hydrogen-bonding stabilization of the acid to the aqueous solution is not being fully accounted for in the model. For the oxalate dianion, the complex receives greater stability from hydrogen-bonding to the aqueous solution, so the deficiency in the model is more pronounced, yielding a slope and intercept that deviates more from 1.0 and 0 , respectively, than that for the parent acid. This suggests that error is expected for the calculated OS complex frequencies, the calculated frequencies for the covalently bonded inner-sphere complexes are expected to have smaller errors.

\subsubsection{Structural assignments of surface complexes by comparison of experimental and calculated vibrational frequencies}

Molecular clusters corresponding to the geometries in Figure 6 are shown in Figure 8, with oxalate bound to clusters of eight Fe atoms representing the (100) and (010) lepidocrocite surfaces, including coordinated $\mathrm{H}_{2} \mathrm{O} / \mathrm{OH}$. Seven additional structures were evaluated, shown in Figure EA10. All structures were energy-minimized, with the analytical frequencies subsequently determined $(B 3 L Y P / 6-31 G(d, p))$. With regards to the bonded oxalate, there were minimal geometry changes between the molecular clusters compared to the periodic cells (Table EA6). The analytical frequencies from the molecular cluster with adsorbed oxalate were subtracted from those of the 
corresponding solvated molecular clusters without oxalate (Figure EA11) to subtract the vibrations of coordinated water. Of the remaining frequencies, only those dominated by an oxalate vibration were considered.

In order to compare calculated analytical frequencies to experiment, the average Gaussian peak positions obtained by Gaussian fitting of the experimental spectra were employed. The theoretical frequencies were then correlated to Gaussian peaks of either $S_{B M}$ or $S_{M M}$ by linear regression (Figure EA12 and Table EA7). Good agreement between experimental and calculated frequencies was indicated by a slope close to 1.0 and an intercept close to 0 . We rejected all structures that lead to slopes $<0.95$ and $>1.05$ and with intercepts deviating from zero by more than $70 \mathrm{~cm}^{-1}$. Structures for which an experimentally observed frequency was not predicted by the calculation were also rejected. An additional measure was the average (absolute) difference between experimental and calculated frequencies.

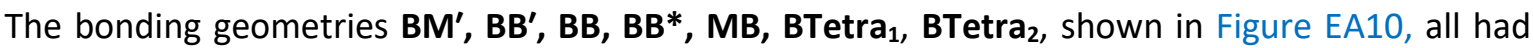
poor correlation or missing frequencies (Figure EA12 and Table EA7) and were not considered further. There was an acceptable correlation for MB, but the experimental frequency at $1664 \pm 9$ $\mathrm{cm}^{-1}$ was not reproduced theoretically, so this configuration was also discounted. Much better correlations and no missing frequencies were obtained for the bonding geometries MM, BM and BTri shown in Figure 8. The linear regression fits for these structures are shown in Figure 9 and the corresponding parameters in Table 1a. Among these structures, BM and $\mathbf{M M}$ had the lowest average differences of all considered structures and are thus the most likely structures formed in agreement with the observed spectra. Surprisingly, between BM and MM, there is no significant difference to the oxalate in geometry, bond order, or Mulliken charges (Tables EA8a,b).

A bonding structure similar to $\mathbf{B M}$ was proposed for oxalate adsorbed to ferrihydrite $(\mathrm{pH}=$ $4.5)$, goethite $(\mathrm{pH}=3.13-7.87)$, hematite $(\mathrm{pH}=5.0)$, boehmite $(\mathrm{pH}=5.1)$, corundum $(\mathrm{pH}=5.1)$. (Axe et al., 2006; Bhandari et al., 2010; Duckworth and Martin, 2001; Yoon et al., 2004). Hug and Sulzberger (Hug and Sulzberger, 1994) had previously postulated the involvement of a protonated $\mathrm{BM}$ and/or $\mathrm{BB}$ structure at low $\mathrm{pH}$ on $\mathrm{TiO}_{2}$, but were unable to explore the idea further. To address this, one of the non-coordiated oxalic $\mathrm{O}$ of the BM cluster was protonated (Figure EA13). The experimental frequencies at $1403 \mathrm{~cm}^{-1}$ and $1684 \mathrm{~cm}^{-1}$ were modeled well, but the frequencies at $1275 \mathrm{~cm}^{-1}$ and $1712 \mathrm{~cm}^{-1}$ were not (average difference from experiment was $23 \mathrm{~cm}^{-1}$ ), and the frequency at $1641 \mathrm{~cm}^{-1}$ was not predicted (Table EA9). It is therefore unlikely that a protonated oxalate is adsorbed to the lepidocrocite surface. Axe (Axe et al., 2006) and Bahndari (Bhandari et al., 2010) had previously suggested that in addition to inner-sphere adsorption, hydrogen-bonded outersphere complexes could also be formed. To explore this, two HOS clusters were built, one modeling the $(010)$ surface $\left(\mathrm{HOS}_{(010)}\right)$ and one modeling the (100) surface $\left(\mathrm{HOS}_{(100)}\right)$ (Figure EA14). Four and five frequencies were predicted for $\mathbf{H O S}_{(010)}$ and $\mathbf{H O S}_{(100)}$, respectively, suggesting that our Sos spectra with only two frequencies arises from a true outer-sphere complex, rather than a hydrogen-bonded complex. For $\mathrm{HOS}_{(010)}$, the theoretical frequencies correlated well with the $\mathrm{S}_{\mathrm{MM}}$ Gaussian peaks (Figure EA15), but for both complexes, the observed frequency at $1664 \mathrm{~cm}^{-1}$ is not reproduced (Table 1). This suggests that while $S_{M M}$ arises from $\mathbf{M M}, \mathbf{H O S}_{(010)}$ could also be present. The correlation of $\operatorname{HOS}_{(100)}$ to $S_{M M}$ is rather poor, suggesting that for the (100) surface, once the oxalate is close enough to directly hydrogen bond to the surface, an inner-sphere complex is immediately formed. The presence of a significant fraction of HOS would be expected to lead to large shifts in peak maxima when $\mathrm{H}_{2} \mathrm{O}$ is replaced with $\mathrm{D}_{2} \mathrm{O}$, while we observed only peak shift in the order of $3-5 \mathrm{~cm}^{-1}$ (Figures $2 \mathrm{c}$ and 2e). Thus, both experiments and calculations provide no evidence for a detectable contribution of HOS from $\mathrm{pH}$ 4-7.

\subsection{Structure and reactivity of different surface complexes}

\subsubsection{Oxalate adsorption $\mathrm{pH}$-edge and ligand promoted dissolution rates}

In the ligand promoted dissolution by oxalate, it is generally assumed that BM complexes have a stronger effect on the kinetic labilization of surface sites. This is consistent with our spectral and 
structural analysis, indicating a decreasing proportion of BM surface complexes and a shift towards less reactive $\mathbf{M M}$ and $\mathrm{OS}$ complexes with increasing $\mathrm{pH}$. In Figure 3, the $\mathrm{pH}$-dependence of the surface concentration of adsorbed oxalate measured in batch experiments is closely matched the by sum of complexes measured by FTIR, while the dissolution rates are matched by the separated spectral contribution of the BM surface complex. This observation confirms that the dissolution rate is not proportional to the sum of adsorbed complexes, but to the concentration of the most reactive surface complex (Banwart et al., 1989).

\subsubsection{Photochemical reactivity}

Dissolved Fe-oxalate complexes are coordinated in a BM structure and show high photoreactivity, with quantum yields of 0.6-1.0 for the formation of $\mathrm{Fe}(\mathrm{II})$ upon irradiation with UV-light (Faust and Zepp, 1993). We could expect similarly high photo-reactivities for BM surface complexes, whereas the photo-reactivities are expected to be lower for BB and MM structures and absent for OS complexes. This is confirmed by our experimental observation in that the spectrum of the rapidly photolyzed complex is most similar to the spectrum of BM. The same spectral features also increase most strongly again after the irradiation stops (Figure 4C). We interpret this as clear evidence for a higher photo-reactivity of the surface complex assigned with a BM structure. During the UVirradiation, the BM complex is photolyzed more quickly than it can reform by equilibration with the less active surface complexes and the oxalate in solution. The equilibrium is re-established after the illumination stops. Interestingly, the spectrum of OS also decreases during irradiation, which could be due electrostatic repulsion of oxalate dianaions from the surface by the photochemical formation of $\mathrm{CO}_{2}^{-}$.

\section{CONCLUSIONS AND IMPLICATIONS}

The combined results of this study show that the formation of several surface complexes of oxalate with different structures is supported both by FTIR-measurements and by DFT-calculations, with good agreement between experimental and calculated frequencies for BM, MM and OS structures. As shown here, the reactivities of these complexes are different and need to be considered in order to understand surface reactions, such as mineral dissolution and photochemical reactions. Isotherms derived from measurements of the overall adsorption of oxalate quantify the surface concentration of adsorbed oxalate, but do not provide information about the speciation and structure of adsorbed oxalate which determine it reactivity. The number of different complexes and their possible structures can be assessed with a combination of experimental and theoretical methods. A series of spectroscopic measurements performed as a function of several variables, such as $\mathrm{pH}$ and time is necessary for a separation of spectra of several surface complexes.

Theoretical calculations with clusters representative of surface sites, performed at the level presented in this study are sufficiently precise to guide the interpretation of the spectra and to identify the major structures that agree best with measured frequencies. However, the correlations between measured frequencies and calculations are often close for several structures. It can thus be difficult to decide whether the different structures exist, or if differences between theory and experiments are sufficient to rule out certain structures. It can also not be ruled out that ranges of different structures are formed and that their spectra exhibit continuous shifts in peak positions as a response to changes in concentration and $\mathrm{pH}$. Even if this is the case, it should still be possible to find a smaller number of spectra and structures that are representative of possible substructures (e.g. structures with different coordinations of water). The limitation to Gaussian line shapes is most likely the main reason for the less than perfect agreement of our fits with the measured spectra. The spectral features between $1600-1650 \mathrm{~cm}^{-1}$ are uncertain due to the difficult subtraction of vibrational bands of water associated with the surface or with surface complexes and should be interpreted with care. Nevertheless, all the experimentally observed important changes in the spectra are reproduced well. In combination with the DFT calculations, it was possible to narrow the important structures of 
surface complexes down to $\mathbf{O S}$, an $\mathbf{M M}$ and a BM.

The proposed structures and spectra can rationalize several independent experimental observations. 1) They explain the observed IR-spectra as a function of time and $\mathrm{pH}$. 2) They explain how ligand-promoted dissolution rates of lepidocrocite with oxalate are not proportional to the total surface concentrations of adsorbed oxalate, but show a much steeper decrease with increasing $\mathrm{pH}$, which is consistent with the expectation that surface complexes with BM structures are the most active in promoting dissolution. 3 ) The expected reactivities of the proposed structures agree with photochemical experiments, which show that the spectral contributions assigned to the BM complex disappears at the fastest rate under UV-irradiation. The BM complex is expected to be similarly photo-reactive as the corresponding solution complex, which is photolyzed with a quantum yield around 0.5 . In contrast, the MM complex is not expected to be nearly as photo-reactive, similarly to surface complexes of malonate and succinate (Borer et al. 2014). Although the IR-spectra with Lp-2 are generally somewhat better defined than with $\mathbf{L p}-\mathbf{1}$, the observed spectral differences are small. The difference of the fractions of dominant crystal faces in our two samples are either too small, or the crystal faces are not ideally crystallized and contain many defect sites that diminish the difference between the different surfaces. This indicates that the overall results and conclusions are likely valid for differently prepared synthetic lepidocrocite samples, and possibly also for naturally occurring lepidocrocite phases.

\section{ACKNOWLEDGEMENTS}

Thomas Ruttimann (Eawag, Switzerland) is acknowledged for assistance with laboratory experiments and ICP-MS analyses. This project was financially supported by the Swiss National Science Foundation under contracts Nos. 200021L_150150 "Synergistic effects of redox processes and ligand controlled dissolution of iron(hydr)oxide phases" Mathematics, Natural sciences and Engineering (division II).

\section{APENDIX A. SUPPLEMENTARY DATA}

Supplementary data associated with this article can be found in the online version.

\section{REFERENCES}

Accelrys Software, I. (2007) Materials Studio. Accelrys Software, Inc., San Diego.

Akutsu, H., Akutsu-Sato, A., Turner, S.S., Day, P., Canadell, E., Firth, S., Clark, R.J.H., Yamada, J.I. and Nakatsuji, S. (2004) Superstructures of donor packing arrangements in a series of molecular charge transfer salts. Chem. Commun. 10, 18-19.

Axe, K. and Persson, P. (2001) Time-dependent surface speciation of oxalate at the water-boehmite (g-AlOOH) interface: Implications for dissolution. Geochim. Cosmochim. Acta 24, 4481-4492.

Axe, K., Vejgården, M. and Persson, P. (2006) An ATR-FTIR spectroscopic study of the competitive adsorption between oxalate and malonate at the water-goethite interface. J. Colloid Interface Sci. 294, 31-37.

Banwart, S., Davies, S. and Stumm, W. (1989) The role of oxalate in accelerating the reductive dissolution of hematite ( $\alpha$-Fe2O3) by ascorbate. Colloids and Surfaces 39, 303-309.

Becke, A.D. (1993) Density-functional thermochemitry. III. The role of exact exchange. J. Chem. Phys. 98, 5648-5652.

Begun, G.M. and Fletcher, W.H. (1963) Vibrational spectra ot aqueous oxalate ion. spectrochimica Acta 19, 1343-1349. 
Bhandari, N., Hausner, D.B., Kubicki, J.D. and Strongin, D.R. (2010) Photodissolution of Ferrihydrite in the Presence of Oxalic Acid: An In Situ ATR-FTIR/DFT Study †. Langmuir 26, 16246-16253.

Blöch, P.E. (1994) Projector Augmented-Wave Method. Phys. Rev. B: Condens. Matter Mater. Phys. 50, 17953-17979.

Borer, P. and Hug, S.J. (2014) Photo-redox reactions of dicarboxylates and $\alpha$-hydroxydicarboxylates at the surface of Fe(III)(hydr)oxides followed with in situ ATR-FTIR spectroscopy. J. Colloid Interface Sci. 416, 44-53.

Borer, P., Hug, S.J., Sulzberger, B., Kraemer, S.M. and Kretzschmar, R. (2007) Photolysis of citrate on the surface of lepidocrocite: An in situ attenuated total reflection infrared spectroscopy study. J. Phys. Chem. C 111, 10560-10569.

Borer, P., Sulzberger, B., Hug, S.J., Kraemer, S.M. and Kretzschmar, R. (2009) Photoreductive dissolution of iron(III) (Hydr)oxides in the absence and presence of organic ligands: Experimental studies and kinetic modeling. Environ. Sci. Technol. 43, 1864-1870.

Cancès, E., Mennucci, B. and Tomasi, J. (1997) A new integral equation formalism for the polarizable continuum model: Theoretical background and applications to Isotropic and anisotropic dielectrics. Journal of Chemical Physics 107, 3032-3041.

Cheah, S.F., Kraemer, S.M., Cervini-Silva, J. and Sposito, G. (2003) Steady-state dissolution kinetics of goethite in the presence of desferrioxamine $B$ and oxalate ligands: Implications for the microbial acquisition of iron. Chem. Geol. 198, 63-75.

Coey, J.M.D., Barry, A., Brotto, J.M., Rakptp, H., Brennan, S., Mussel, W.N., Collomb, A. and Fruchart, D. (1995) Spin Flip in Goethite. J. Phys. 7, 759-768.

Cornell, R.M. and Schwertmann, U. (2003) The Iron Oxides: Structure, Properties, Reactions, Occurrences, and Uses, 2nd ed.; ed. Wiley-VCH, New York, NY, USA.

Cwiertny, D.M., Hunter, G.J., Pettibone, J.M., Scherer, M.M. and Grassian, V.H. (2009) Surface chemistry and dissolution of \&alpha;-FeOOH nanorods and microrods: Environmental implications of size-dependent interactions with oxalate. J. Phys. Chem. C 113, 2175-2186.

Degenhardt, J. and McQuillan, A.J. (1999) Mechanism of oxalate ion adsorption on chromium oxidehydroxide from pH dependence and time evolution of ATR-IR spectra. Chem. Phys. Lett. 311, 179184.

Deutsch, F., Hoffmann, P. and Ortner, H.M. (2001) Field experimental investigations on the Fe(II)- and $\mathrm{Fe}(\mathrm{III})$-content in cloudwater samples. J. Atmos. Chem. 40, 87-105.

Domagal-Goldman, S.D. and Kubicki, J.D. (2008) Density functional theory predictions of equilibrium isotope fractionation of iron due to redox changes and organic complexation. Geochim. Cosmochim. Acta 72, 5201-5216.

Duckworth, O.W. and Martin, S. (2001) Surface complexation and dissolutino of hematite by C1-C6 dicarboxylic acids at $\mathrm{pH}=5.0$. Geochim. Cosmochim. Acta 65, 4289-4301.

Dudarev, S.L., Botton, G.A., Savrasov, S.Y., Humpherys, C.J. and Sutton, A.P. (1998) Electron-EnergyLoss Spectra and the Structural Stability of Nickel Oxide: An LSDA+U Study. Phys. Rev. B: Condens. Matter Mater. Phys. 57, 1505-1509.

Faust, B.C. and Zepp, R.G. (1993) Photochemistry of aqueous iron(III)-polycarboxylate complexes: Roles in the chemistry of atmospheric and surface waters. Environ. Sci. Technol. 27, 2517-2522.

Frisch, M.J., Trucks, G.W., Schlegel, H.B., Scuseria, G.E., Robb, M.A., Cheeseman, J.R., Scalmani, G., Barone, V., Mennucci, B., Petersson, G.A., Nakatsuji, H., Caricato, M., Li, X., Hratchian, H.P., Izmaylov, A.F., Bloino, J., Zheng, G., Sonnenberg, J.L., Hada, M., Ehara, M., Toyota, K., Fukuda, R., Hasegawa, J., Ishida, M., Nakajima, T., Honda, Y., Kitao, O., Nakai, H., Vreven, T., Montgomery, J.A., Jr., Peralta, J.E., Ogliaro, F., Bearpark, M., Heyd, J.J., Brothers, E., Kudin, K.N., Staroverov, V.N., Kobayashi, R., Normand, J., Raghavachari, K., Rendell, A., Burant, J.C., Iyengar, S.S., Tomasi, J., Cossi, M., Rega, N., Millam, J.M., Klene, M., Knox, J.E., Cross, J.B., Bakken, V., Adamo, C., Jaramillo, J., Gomperts, R., Stratmann, R.E., Yazyev, O., Austin, A.J., Cammi, R., Pomelli, C., Ochterski, J.W., Martin, R.L., Morokuma, K., Zakrzewski, V.G., Voth, G.A., Salvador, P., Dannenberg, J.J., Dapprich, S., Daniels, A.D., Farkas, Ö., Foresman, J.B., Ortiz, J.V., Cioslowski, J. and Fox, D.J. Gaussian 09, Revision D.01. Gaussian.Inc., Wallingford, CT. 
Fujita, J., Martell, A.E. and Nakamoto, K. (1962a) Infrared spectra of metal chelate compounds. VI. A normal coordinate treatment of oxalato metal complexes. J. Chem. Phys. 36, 324-331.

Fujita, J., Martell, A.E. and Nakamoto, K. (1962b) Infrared spectra of metal chelate compounds. VII. Normal coordinate treatments on 1:2 and 1:3 oxalato complexes. J. Chem. Phys. 36, 331-338.

Gouteron, J. (1976) Spectres de vibration de composes de coordination trichelates-I Composes trioxaliques. Journal of Inorganic and Nuclear Chemistry 38, 55-61.

Gusain, D., Srivastava, V., SillanpÃßãß, M. and Sharma, Y.C. (2016) Kinetics and isotherm study on adsorption of chromium on nano crystalline iron oxide/hydroxide: linear and nonlinear analysis of isotherm and kinetic parameters. Res Chem Intermed 42, 7133-7151.

Hansmann, D.D. and Anderson, M.A. (1985) Using electrophoresis in modeling sulfate, selenite, and phosphate adsorption onto goethite. Environ. Sci. Technol. 19, 544-551.

Hiemstra, T. and van Riemsdijk, W.H. (2007) Adsorption and surface oxidation of Fe(II) on metal (hydr)oxides. Geochim. Cosmochim. Acta 71, 5913-5933.

Hind, A.R., Bhargava, S.K., Van Bronswijk, W., Grocott, S.C. and Eyer, S.L. (1998) On the Aqueous Vibrational Spectra of Alkali Metal Oxalates. Applied Spectroscopy 52, 683-691.

Homborg, H. and Preetz, W. (1976) Tieftemperatur-Raman-Messungen an rotierenden festen Proben. Spectrochim. Acta Part A Mol. Spectrosc. 32, 709-716.

Hug, S.J. and Bahnemann, D. (2006) Infrared spectra of oxalate, malonate and succinate adsorbed on the aqueous surface of rutile, anatase and lepidocrocite measured with in situ ATR-FTIR. J Electron Spectrosc Relat Phenom 150, 208-219.

Hug, S.J. and Sulzberger, B. (1994) In situ Fourier transform infrared spectroscopic evidence for the formation of several different surface complexes of oxalate on $\mathrm{TiO} 2$ in the aqueous phase. Langmuir 10, 3587-3597.

Humphrey, W., Dalke, A. and Schulten, K. (1996) VMD: visual molecular dynamics. J. Mol. Graphics Modell. 14, 33-38.

Kraemer, S.M. (2004) Iron oxide dissolution and solubility in the presence of siderophores. Aquatic Sci. 66, 3-18.

Kresse, G. and Furthmüller, J. (1996) Efficient Iterative Schemes for Ab Initio Total-Energy Calculations Using a Plane-Wave Basis Set. Phys. Rev. B: Condens. Matter Mater. Phys. 54, 11169-11186.

Kresse, G. and Joubert, D. (1999) From Ultrasoft Pseuodopotentials to the Projector AugmentedWave Method. Phys. Rev. B: Condens. Matter Mater. Phys. 59, 1758-1775.

Kubicki, J.D. (2006) Comparison of As(III) and As(V) complexation onto Al- And Fe-hydroxides, in: O'Day, P.A., Vlassopoulos, D., Meng, X., Benning, L.G. (Eds.), ACS Symposium Series, 915, pp. 104117.

Kubicki, J.D., Paul, K.W., Kabalan, L., Zhu, Q., Mrozik, M.K., Aryanpour, M., Pierre-Louis, A.M. and Strongin, D.R. (2012) ATR-FTIR and density functional theory study of the structures, energetics, and vibrational spectra of phosphate adsorbed onto goethite. Langmuir 28, 14573-14587.

Kubicki, J.D., Paul, K.W. and Sparks, D.L. (2008) Periodic density functional theory calculations of bulk and the (010) surface of goethite. Geochemical Transactions 9, 4.

Laasonen, K., Car, R., Lee, C. and Vanderbilt, D. (1991) Implementation of Ultrasoft Pseudopotentials in Ab Initio Molecular Dynamics. Phys. Rev. B: Condens. Matter Mater. Phys. 43, 6796-6799.

Lee, C., Yang, W. and Parr, R.G. (1988) Development of the Colle-Salvetti correlation-energy formula into a functional of the electron density. Phys. Rev. B 37, 785-789.

Loring, J.S., Simanova, A.A. and Persson, P. (2008) Highly mobile iron pool from a dissolutionreadsorption process. Langmuir 24, 7054-7057.

Martin, A. and Pinkerton, A.A. (1998) Charge density studied using CCD detectors: Oxalic acid at 100 $K$ revisited. Acta Cryst B54, 471-477.

Mendive, C.B., Bredow, T., Feldhoff, A., Blesa, M.A. and Bahnemann, D. (2009) Adsorption of oxalate on anatase (100) and rutile (110) surfaces in aqueous systems: Experimental results vs. theoretical predictions. Phys. Chem. Chem. Phys. 11, 1794-1808. 
Öhrström, L. and Michaud-Soret, I. (1999) Fe - Catecholate and Fe - Oxalate Vibrations and Isotopic Substitution Shifts from DFT Quantum Chemistry. J Phys Chem A 103, 256-264.

Otte, K., Schmahl, W.W. and Pentcheva, R. (2013) DFT+ U study of arsenate adsorption on FeOOH surfaces: Evidence for competing binding mechanisms. J. Phys. Chem. C 117, 15571-15582.

Perdew, J.P., Burke, K. and Ernzerhof, M. (1997) Errata: Generalized gradient approximation made simple. Phys. Rev. Lett. 78, 1396.

Perdew, J.P.p., Burke, K. and Ernzerhof, M. (1996) Generalized Gradient Approximation Made Simple. Phys. Rev. Lett. 77, 3865-3868.

Persson, P. and Axe, K. (2005) Adsorption of oxalate and malonate at the water-goethite interface: Molecular surface speciation from IR spectroscopy. Geochim. Cosmochim. Acta 69, 541-552.

Rassolov, V.A., Ratner, M.A., Pople, J.A., Redfern, P.C. and Curtiss, L.A. (2001) 6-31G* Basis Set for Third-Row Atoms. J. Comput. Chem. 22, 976-984.

Reichard, P.U., Kretzschmar, R. and Kraemer, S.M. (2007) Dissolution mechanisms of goethite in the presence of siderophores and organic acids. Geochim. Cosmochim. Acta 71, 5635-5650.

Schwertmann, U. and Cornell, R.M. (2000) Iron Oxides in the Laboratory, 2nd, Completely Revised and Extended Edition ed. Wiley-VCH Weinheim, Germany.

Scott, A.P. and L, R. (1996) Harmonic Vibrational Frequencies: An Evaluation of Hartree-Fock, MøllerPlesset Quadratic Configuration Interaction, Density Functional Theory, and Semi-Empirical Scale Factors. 100, 16502-16513.

Shippey, T.A. (1980) Vibrational studies in aqueous solutions. journal of molecular structure 65, 7186.

Simanova, A.A., Loring, J.S. and Persson, P. (2011) Formation of ternary metal-oxalate surface complexes on $\alpha-\mathrm{FeOOH}$ particles. J. Phys. Chem. C 115, 21191-21198.

Situm, A., Rahman, M.A., Goldberg, S. and Al-Abadleh, H.A. (2016) Spectral characterization and surface complexation modeling of low molecular weight organics on hematite nanoparticles: Role of electrolytes in the binding mechanism. Environmental Science: Nano 3, 910-926.

Sulzberger, B. and Laubscher, H. (1995) Reactivity of various types of iron(III) (hydr)oxides towards light-induced dissolution. Mar. Chem. 50, 103-115.

Yoon, T.H., Johnson, S.B., Musgrave, C.B. and Brown, J.G.E. (2004) Adsorption of organic matter at mineral/water interfaces: I. ATR-FTIR spectroscopic and quantum chemical study of oxalate adsorbed at boehmite/water and corundum/water interfaces. Geochim. Cosmochim. Acta 68, 4505-4518.

Young, A.G. and McQuillan, A.J. (2009) Adsorption/desorption kinetics from ATR-IR spectroscopy. Aqueous oxalic acid on anatase TiO2. Langmuir 25, 3538-3548. 


\section{TABLES AND FIGURES}

Table 1. Comparison of experimental and theoretical IR frequencies $\left(\mathrm{cm}^{-1}\right)$ of inner-sphere and outer-sphere bonding geometries of oxalate to lepidocrocite for molecular clusters.

\begin{tabular}{|c|c|c|c|c|c|c|c|}
\hline \multirow{2}{*}{ Modes } & \multirow{2}{*}{$\begin{array}{l}\text { experimental } \\
\text { frequencies }\end{array}$} & \multicolumn{6}{|c|}{ theoretical frequencies } \\
\hline & & BTri $_{(010)}$ & $\mathrm{BM}_{(100)}$ & $\mathrm{MM}_{(100)}$ & $\mathrm{HOS}_{(010)}$ & $\mathrm{HOS}_{(100)}$ & $\mathrm{OS}$ \\
\hline$v_{s}(\mathrm{C}-\mathrm{O})$ & $1275 \pm 6$ & $1252(-23)$ & $1281(6)$ & - & - & - & - \\
\hline$v_{s}(\mathrm{C}-\mathrm{O})$ & $1286 \pm 4$ & - & - & $1285(-1)$ & $1278(-8)$ & $1301(15)$ & - \\
\hline$v_{a}(C-O)$ & $1308 \pm 1$ & - & - & - & - & - & $1286(-22)$ \\
\hline$v_{a}(\mathrm{C}-\mathrm{O})$ & $1403 \pm 4$ & $1375(-28)$ & $1406(3)$ & - & - & - & - \\
\hline$v_{a}(C-O)$ & $1422 \pm 4$ & - & - & $1418(-4)$ & $1415(-7)$ & $1457(35)$ & - \\
\hline$v_{a}(C-O)$ & $1567 \pm 7$ & - & - & - & - & - & $1565(-2)$ \\
\hline$v_{a}(C-O)$ & - & - & - & $1575^{\star}$ & 1552 & 1569 & - \\
\hline$v_{a}(C=O)$ & $1609 \pm 18$ & - & - & $1609(0)$ & $1604(-5)$ & $1585(-24)$ & - \\
\hline$v_{a}(C=O)$ & $1641 \pm 28$ & $1626(-15)$ & $1632(-9)$ & - & - & - & - \\
\hline$v_{a}(C=O)$ & $1664 \pm 9$ & - & - & $1641(-23)$ & missing & missing & - \\
\hline$v_{a}(C=O)$ & $1684 \pm 3$ & $1673(-11)$ & $1683(-1)$ & - & - & - & - \\
\hline \multirow[t]{3}{*}{$v_{a}(C=O)$} & $1712 \pm 1$ & $1686(-26)$ & $1698(-14)$ & - & - & $1711(-1)$ & - \\
\hline & $R^{2}$ & 0.999 & 0.999 & 0.998 & 0.999 & 0.987 & - \\
\hline & $\begin{array}{r}\text { slope } \\
\text { y-intercept } \\
\text { age difference }\end{array}$ & $\begin{array}{c}1.014 \\
-41.927 \\
\mathbf{2 0 . 3} \\
\end{array}$ & $\begin{array}{c}0.959 \\
59.668 \\
\mathbf{6 . 9}\end{array}$ & $\begin{array}{c}0.959 \\
53.237 \\
7.3\end{array}$ & $\begin{array}{c}1.002 \\
-9.149 \\
6.5 \\
\end{array}$ & $\begin{array}{l}0.915 \\
134.409 \\
\mathbf{2 5 . 7} \\
\end{array}$ & $\begin{array}{l}- \\
- \\
-\end{array}$ \\
\hline
\end{tabular}

Listed in the second column are the rounded means and standard deviations of the experimentally determined frequencies by Gaussian peak fitting of different data sets. Gaussian peaks assigned to $S_{B M}$ are listed in red, Gaussian peaks assigned to $\mathrm{S}_{\mathrm{MM}}$ in blue, and Gaussian peaks assigned to $\mathrm{S}_{\mathrm{O}}$ in green. Rounded differences between the mean experimental and the theoretical frequencies are given in parentheses. ( ${ }^{*}$ The frequency at $1575 \mathrm{~cm}^{-1}$ for MM was not used, because it is too close to the observed $S_{O S}$ band at $1565 \mathrm{~cm}^{-1}$ and the absorbance at around $1575 \mathrm{~cm}^{-1}$ is too featureless for the assignment of an additional peak position).

Table 2. Calculated relative stability of "dry" surface model and adsorption energy ( $\left.\Delta E_{\text {ads }}\right)$ of "solvated" surface model $\left(\mathrm{kJ} \mathrm{mol}^{-1}\right)$.

\begin{tabular}{cccccc}
\hline (010) & $\begin{array}{c}\text { Relative } \\
\text { Stability } \\
\text { (dry) }\end{array}$ & $\begin{array}{c}\text { Adsorption } \\
\text { Energy } \\
\text { (solvated) }\end{array}$ & $(100)$ & $\begin{array}{c}\text { Relative } \\
\text { Stability } \\
\text { (dry) }\end{array}$ & $\begin{array}{c}\text { Adsorption } \\
\text { Energy } \\
\text { (solvated) }\end{array}$ \\
\hline BTetra 1 & 113 & - & BB $^{*}$ & 146 & - \\
BTetra 2 & 71 & - & BB & 314 & - \\
- & - & - & BM $^{\prime}$ & 100 & - \\
BTri & 0 & +29 & BM & 0 & -89 \\
MB & 163 & - & MM & 92 & -98 \\
\hline
\end{tabular}

$\Delta E_{\text {ads }}=E$ (outer sphere) $-E$ (inner sphere), a negative value favors adsorption.

Note: calculated $\Delta E_{\text {ads }}$ do not consider entropy changes with adsorption. 

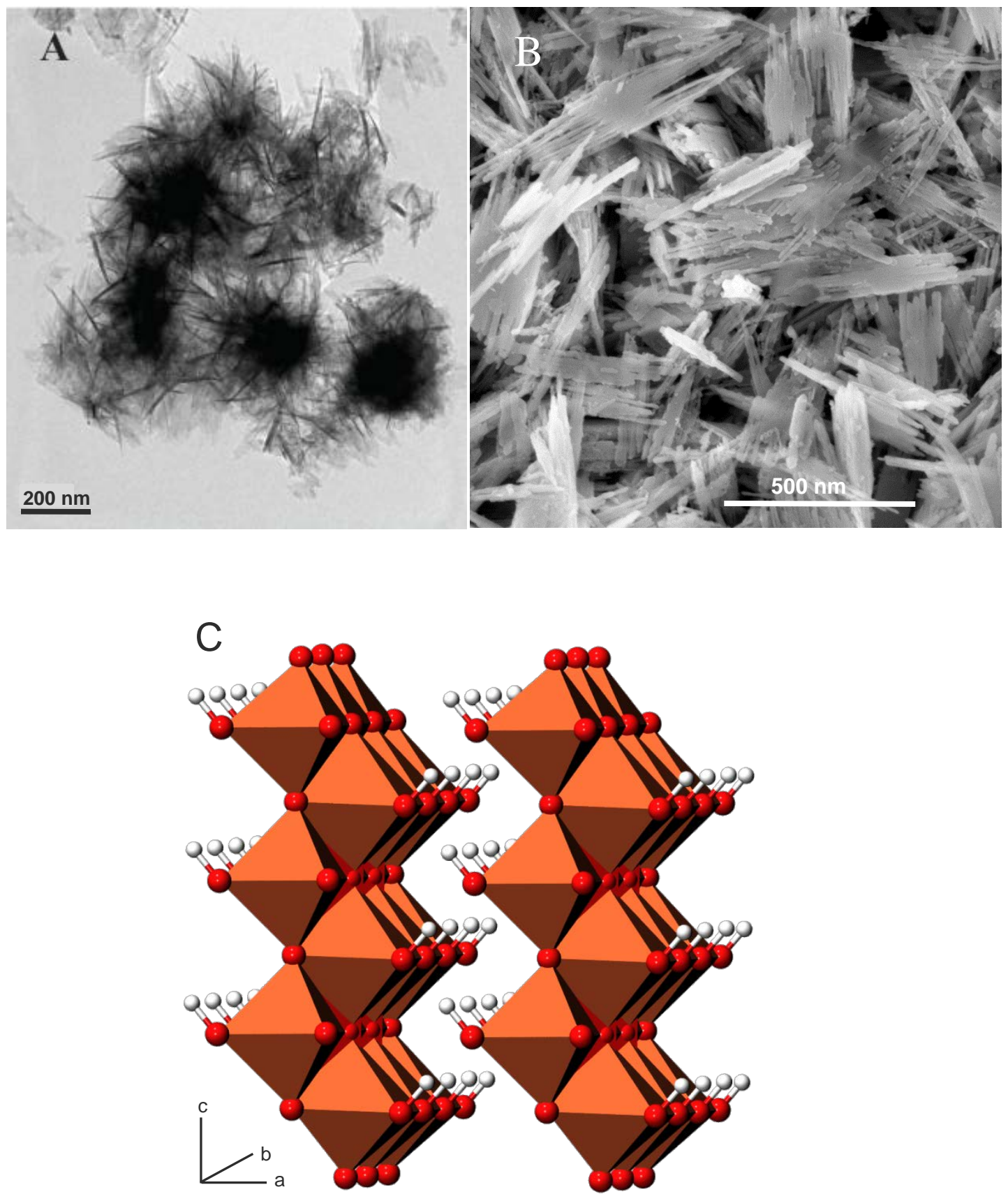

Figure 1. EM images of the lepidocrocite samples, and structure. (A) Lp-1 prepared according to the method of Brauer (1963), TEM image adapted from Borer et al. (2009). (B) Lp-2 synthesized according to Schwertmann and Cornell (2000). SEM image recorded on FEI Magellan 400, USA, with in-lens detector operated at 3kV.

(C) Lepidocrocite structure with (100) surface in paper plane. 

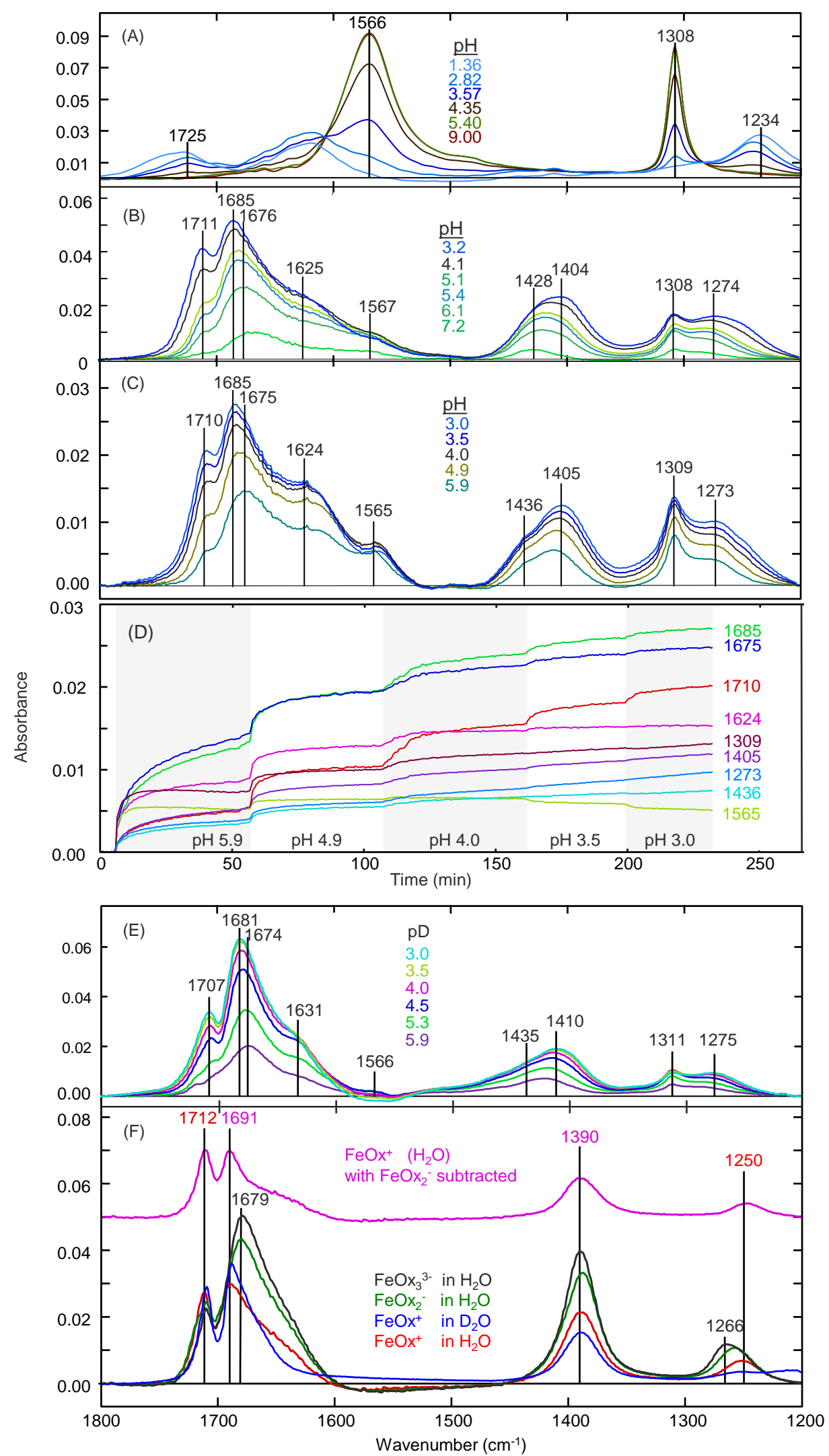

Figure 2. Background-subtracted ATR-FTIR absorbance spectra. (A) Aqueous solution of oxalic acid (50 mM) starting at $\mathrm{pH} 1.36$ and titrated up to $\mathrm{pH}$ 9.00. (Adapted from Hug and Sulzberger (Hug and Sulzberger, 1994)).(B) and (C) Adsorption of aqueous oxalate $(200 \mu \mathrm{M}, I=10 \mathrm{mM} \mathrm{KCl})$ on Lp-1 and Lp-2, respectively, at various $\mathrm{pH}$ values, close to equilibrium. (D) Kinetics of oxalate adsorption on Lp-2 followed at different peak positions, as indicated in the plots (scans taken every 41.3 seconds). (E) Adsorption of oxalate on $\mathbf{L p}-\mathbf{2}$ in $\mathrm{D}_{2} \mathrm{O}$ $(200 \mu \mathrm{M}, l=10 \mathrm{mM} \mathrm{NaCl})$ at pD 3.0-5.9. (F) Aqueous Fe-oxalate complexes as indicated in the figure, $10 \mathrm{mM}$ in $\mathrm{H}_{2} \mathrm{O}$ and $50 \mathrm{mM}$ in $\mathrm{D}_{2} \mathrm{O}$, scaled to similar amplitudes at $1712 \mathrm{~cm}^{-1}$. 


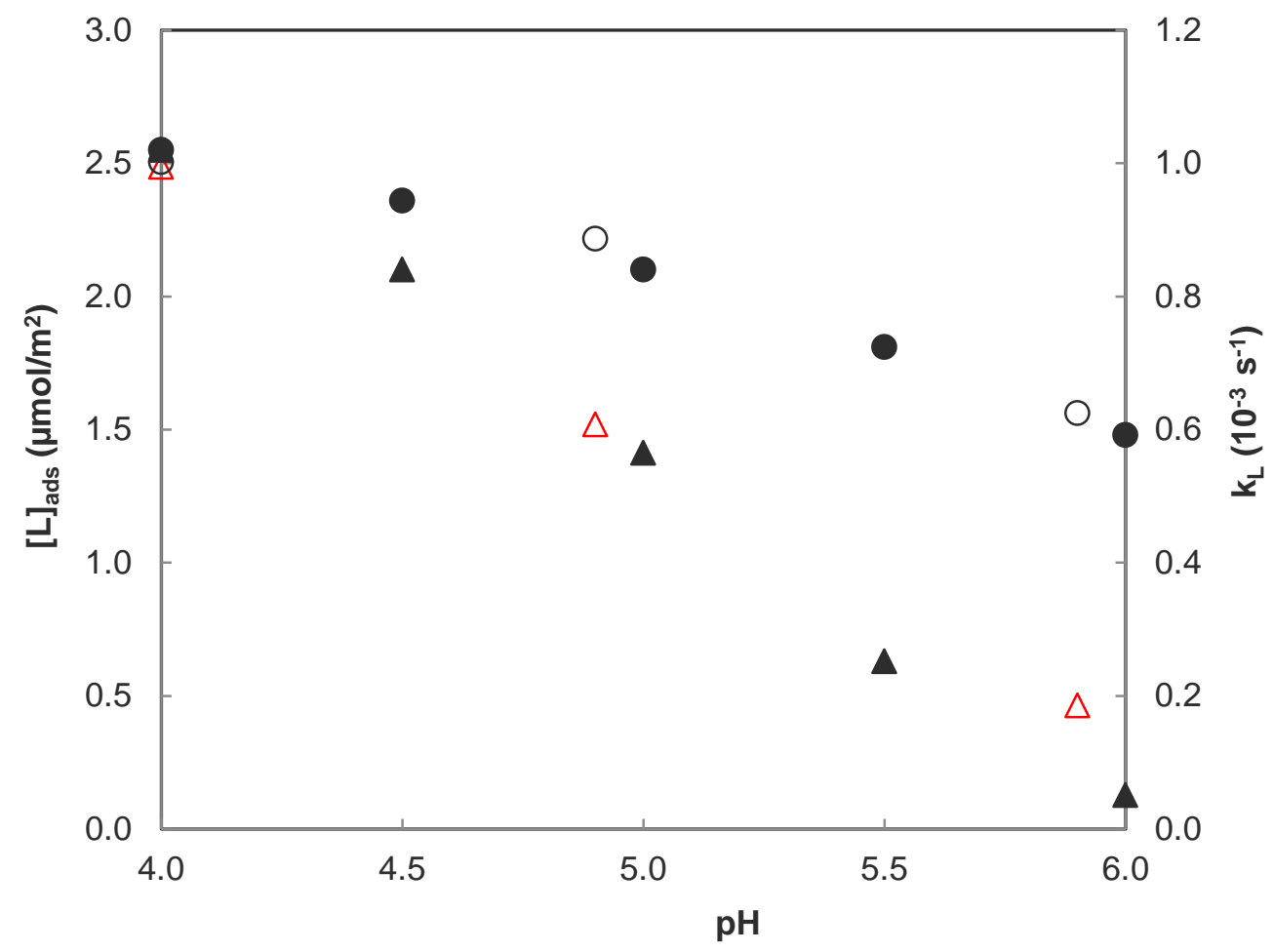

Figure 3. Effect of pH on adsorption of oxalate on Lp-2 (filled black circles, left y-axis) and rate coefficients (filled black triangles, right $\mathrm{y}$-axis) of ligand controlled dissolution. Total oxalate concentrations were $500 \mu \mathrm{M}$ in $0.01 \mathrm{M}$ $\mathrm{NaCl}$ solution at solids concentrations of $0.1 \mathrm{~g} \mathrm{~L}^{-1}$ (adsorption and dissolution experiments). The empty red triangles show the contributions of $\mathrm{BM}$ and the empty black circles the sum of the contributions of $\mathrm{BM}, \mathrm{MM}$ and $\mathrm{OS}$, scaled to an amplitude of $2.5 \mu \mathrm{mol} \mathrm{m}{ }^{-2}$ at $\mathrm{pH} 4.0$ for easier comparison. 

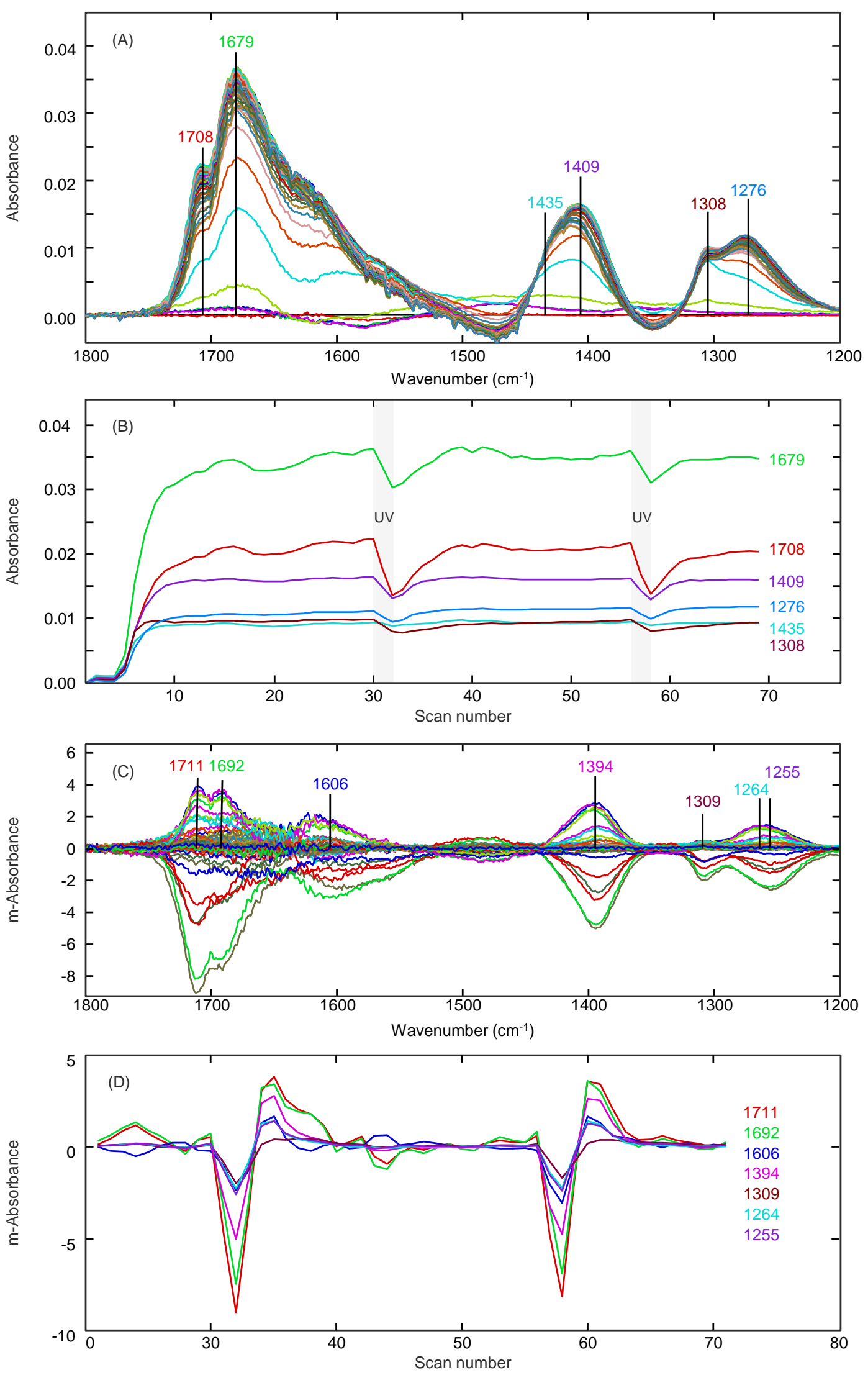

Figure 4. Adsorption of oxalate $(200 \mu \mathrm{M})$ on Lp-1 and illumination with $365 \mathrm{~nm}$ UV-light at pH 4.0. (A) Spectra during adsorption and illumination (scans every 71 seconds). (B) Kinetics measured at the wavelengths indicated. (C) Spectral differences during illumination (negative amplitudes) and during re-equilibration (positive amplitudes). (D) Kinetics of the differences at the wavelengths indicated as a function of time. The spectral differences in (C) resemble the spectral characteristics of FeOx ${ }^{+}$and of the Gaussian spectrum BM, while the changes in the spectral range of the MM-spectrum are much smaller. This indicates that the BM is the most photo-active surface complex. 

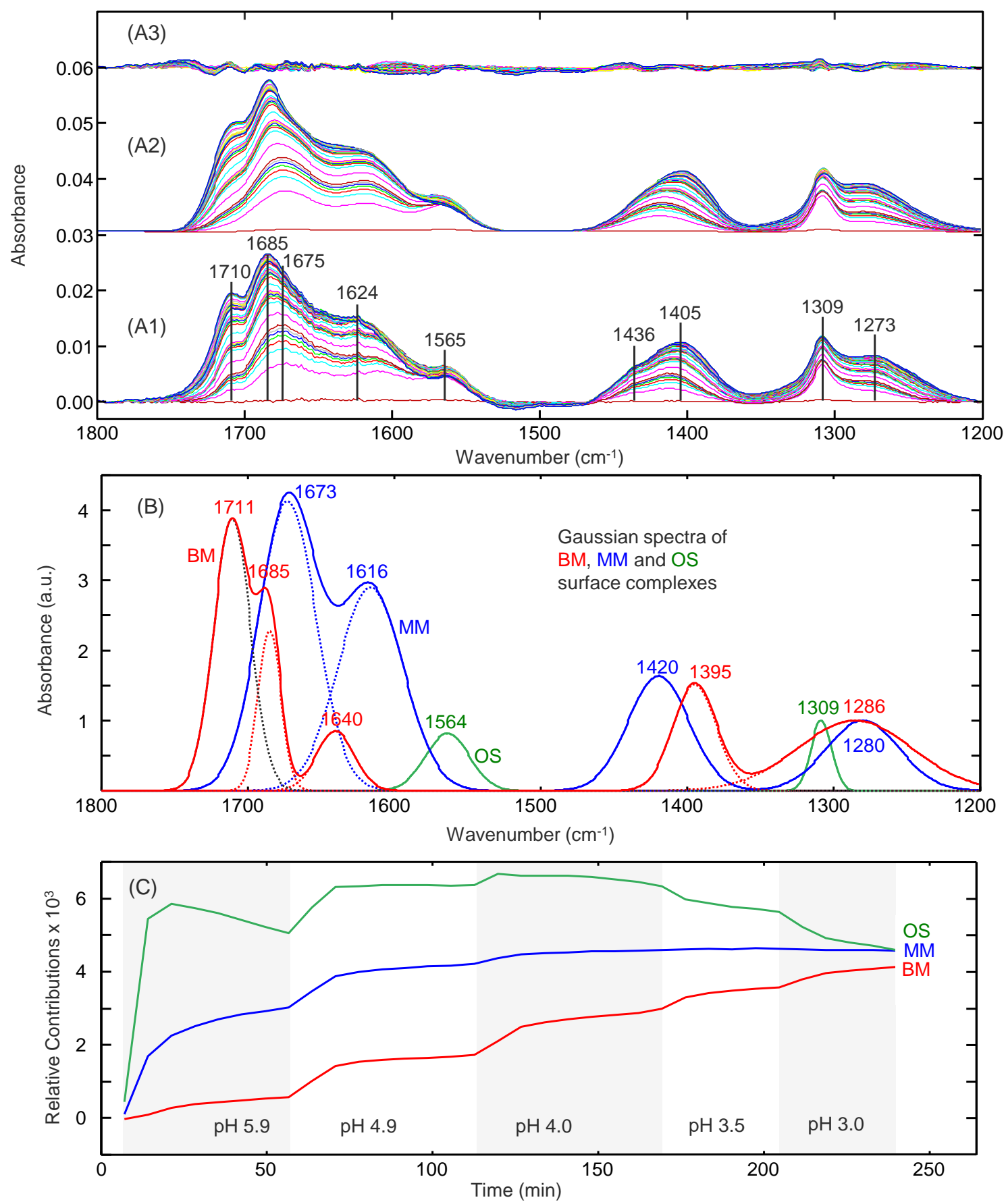

Figure 5. Adsorption of oxalate $(200 \mu \mathrm{M}, \mathrm{l}=10 \mathrm{mM} \mathrm{NaCl})$ on $\mathbf{L p}-\mathbf{2}$ and spectral fits. (A1) Absorbance as a function of time and $\mathrm{pH}$ (spectra measured every 41.3 seconds). The data set is the same as in Figure $2 \mathrm{C}$, but spectra at more times are shown. (A2) reconstructed spectra with Gaussian line shapes (offset by 0.03 abs. units) and (A3) residuals (measured minus reconstructed spectra), offset by 0.06 abs. units). (B) Gaussian fits with five possible peaks for the spectrum of BM, four possible peaks for the spectrum of $\mathrm{MM}$, and two possible peaks for the spectrum of OS. (C) Contributions of BM, MM, and OS as a function of time and pH. 
(100)
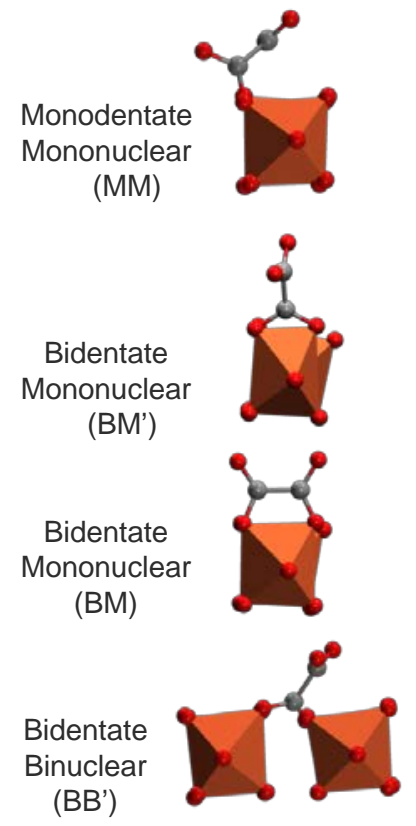

Bidentate
Binclear
(BB)

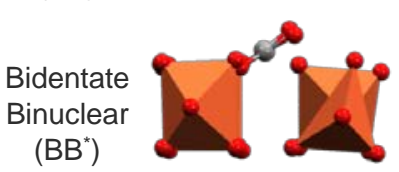

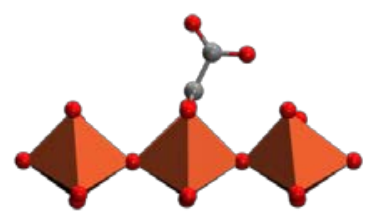
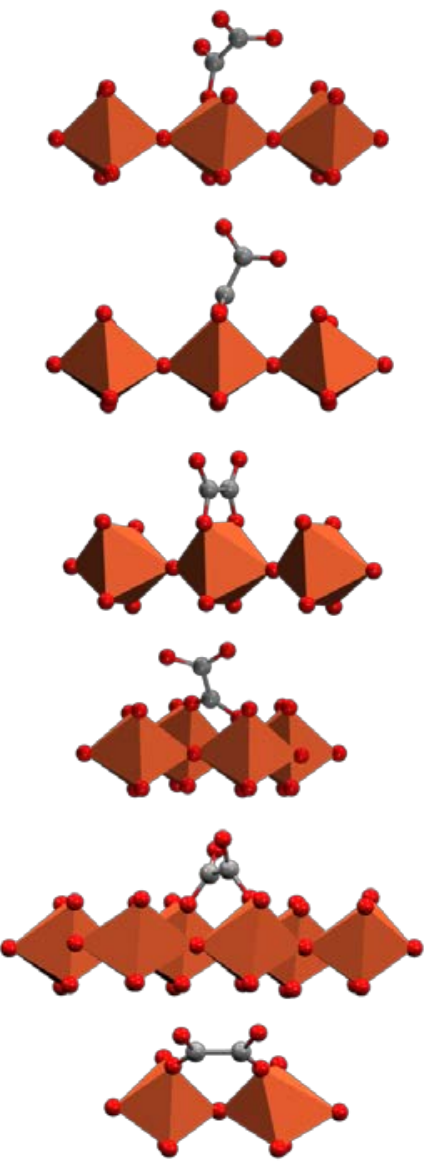

(010)

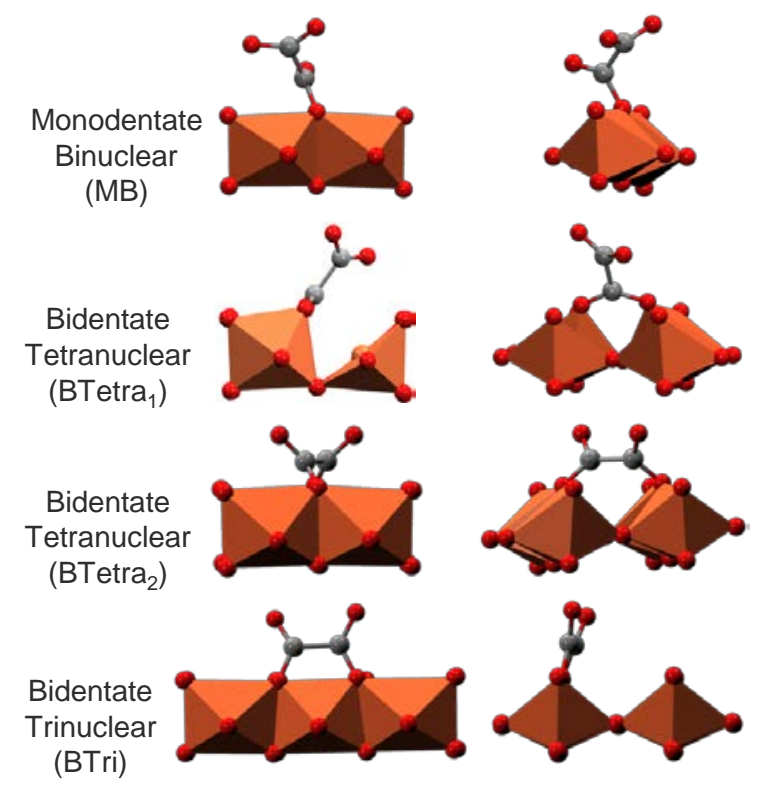

Figure 6. Possible bonding structures of oxalate adsorbed to lepidocrocite (010) and (100) surfaces.

$\mathrm{Fe}$ atoms are represented by orange polyhedrons, $\mathrm{O}$ and $\mathrm{C}$ atoms are represented by red and gray spheres, respectively. $\mathrm{H}$ atoms are omitted. 
a)

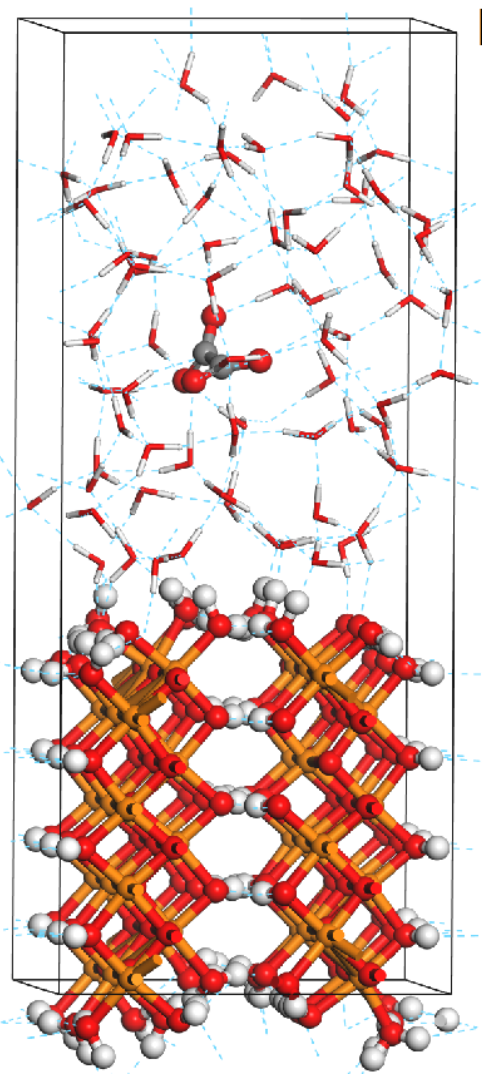

b)

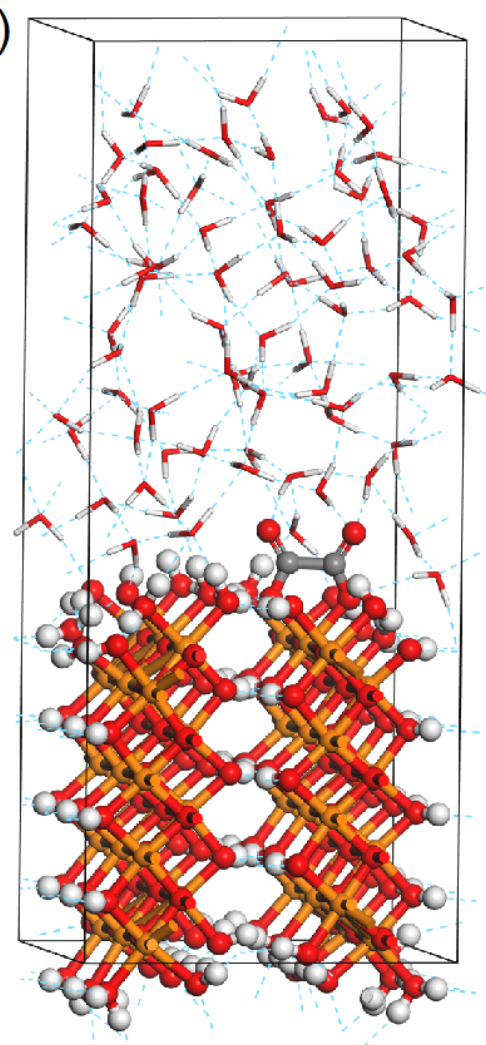

c)

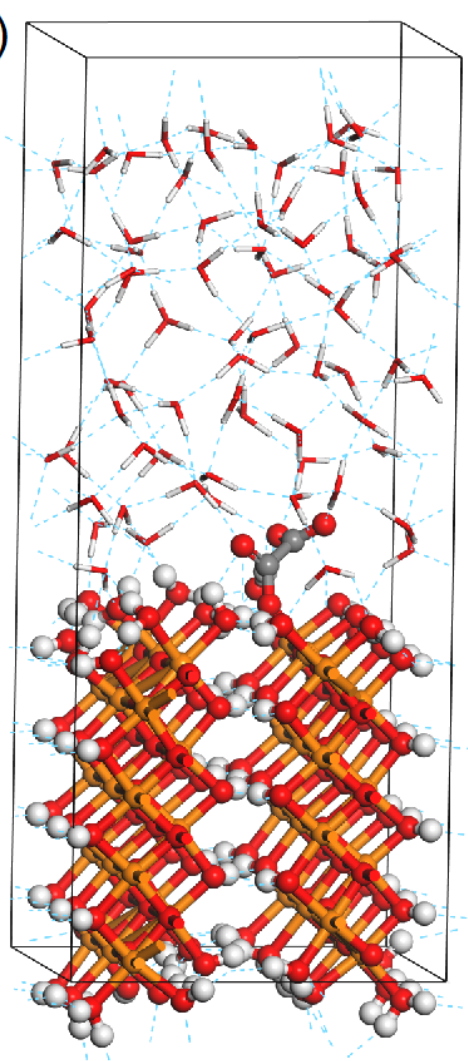

Figure 7. (a) Aqueous (OS), (b) BM, and (c) MM bonding configurations of "solvated" lepidocrocite (100) $\left(\mathrm{Fe}_{48} \mathrm{O}_{195} \mathrm{H}_{240} \mathrm{C}_{2}\right)$. Fe, $\mathrm{O}, \mathrm{C}$, and $\mathrm{H}$ atoms are represented by orange, red, gray and white colors, respectively. The lepidocrocite layer is represented in a ball \& stick style, while the hydrogen-bonded water molecules are represented in a licorice style. View with (001) surface in paper plane, looking down c-axis, 100 surface on top.

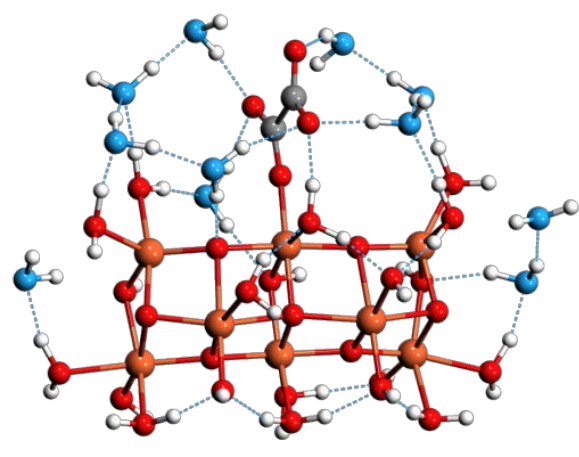

MM (100)

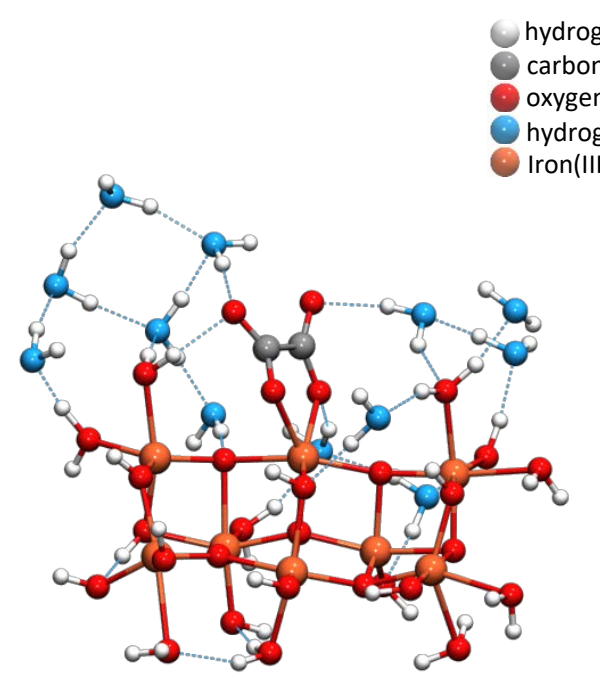

BM (100)

hydrogen
carbon
oxygen
hydrogen-bonded oxygen
Iron(III)

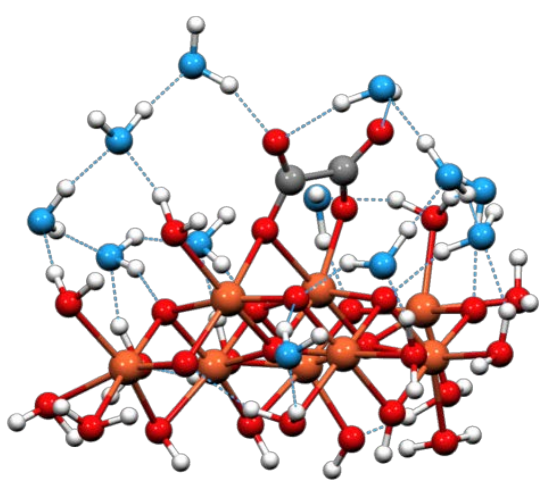

BTri (010)

Figure 8. Geometry-optimized molecular clusters $\left(\mathrm{C}_{2} \mathrm{H}_{54} \mathrm{O}_{42} \mathrm{Fe} 8\right)$ representing (010) and (100) surfaces,

respectively, with $M M, B M$ and $B$ Tri structures. Calculated at the $B 3 L Y P / 6-31 G(d, p)$ level in the gas phase. 


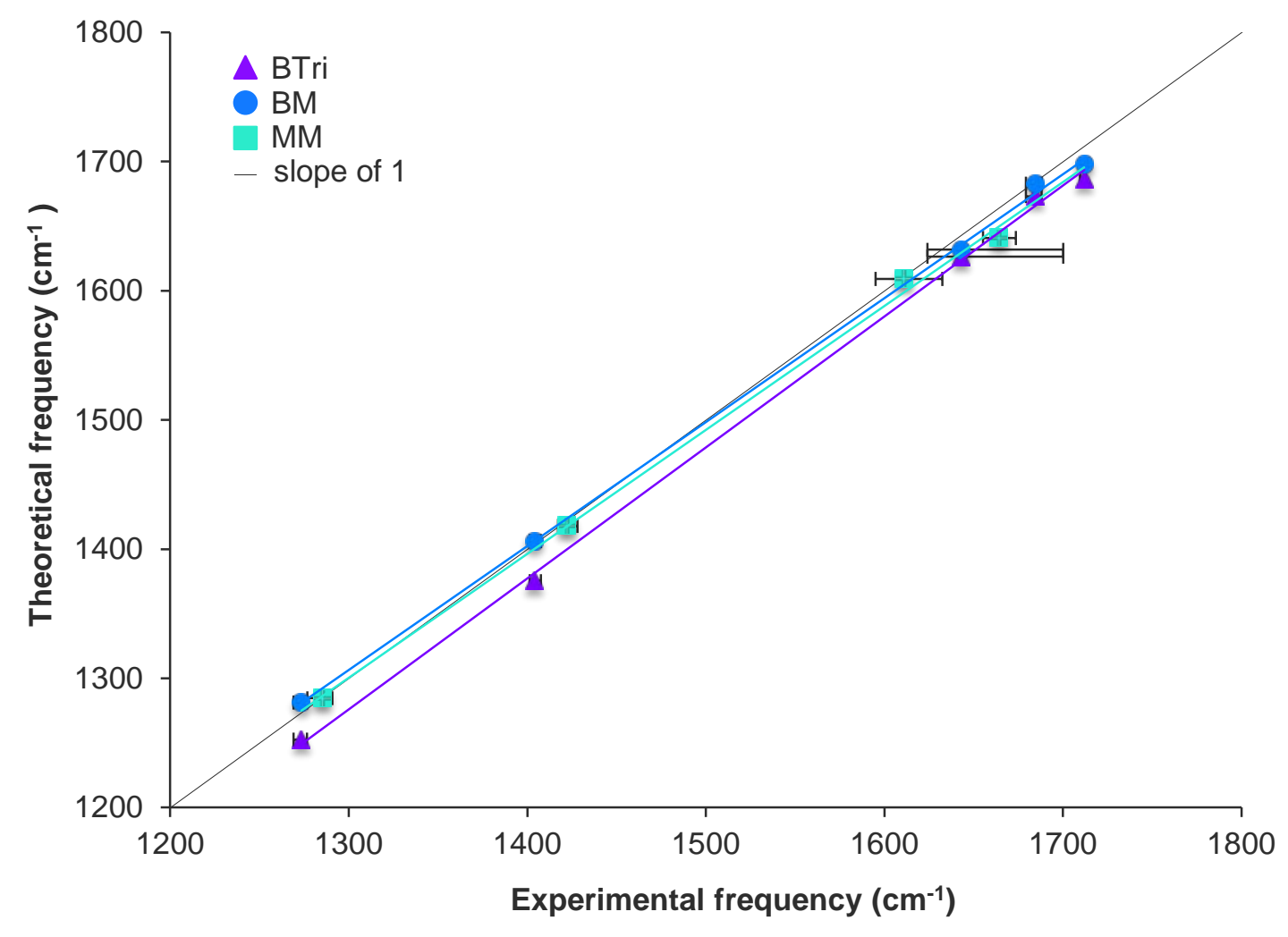

Figure 9. Linear regression comparison of experimental and theoretical frequencies of BTri, BM, and MM. Linear fit parameters are given in Table 1a. 